NBER WORKING PAPER SERIES

\title{
INCOME CHANGES AND INTIMATE PARTNER VIOLENCE: EVIDENCE FROM UNCONDITIONAL CASH TRANSFERS IN KENYA
}

\author{
Johannes Haushofer \\ Charlotte Ringdal \\ Jeremy P. Shapiro \\ Xiao Yu Wang \\ Working Paper 25627 \\ http://www.nber.org/papers/w25627 \\ NATIONAL BUREAU OF ECONOMIC RESEARCH \\ 1050 Massachusetts Avenue \\ Cambridge, MA 02138 \\ March 2019, Revised July 2019
}

We are deeply grateful to Justin Abraham, Faizan Diwan, Conor Hughes, Victoria Isika, and James Reisinger for outstanding project management and data analysis. We further thank the study participants for generously giving their time; Marie Collins, Chaning Jang, Bena Mwongeli, Joseph Njoroge, Kenneth Okumu, James Vancel, and Matthew White for excellent research assistance; Allan Hsiao and Emilio Dal Re for data and code auditing; the team of GiveDirectly (Michael Cooke, Michael Faye, Raphael Gitau, Piali Mukhopadhyay, Paul Niehaus, Joy Sun, Carolina Toth, Rohit Wanchoo) for fruitful collaboration; Petra Persson for help in designing the intrahousehold bargaining and domestic violence module; Claire Cullen, Melissa Hidrobo, Chaning Jang, Urla Krenk, Michala Riis-Vestergaard, Christopher Roth, Anna Tompsett, and seminar participants at various institutions for comments and discussion. All errors are our own. This research was supported by NIH Grant R01AG039297 and Cogito Foundation Grant R-116/10 to Johannes Haushofer. The views expressed herein are those of the authors and do not necessarily reflect the views of the National Bureau of Economic Research.

NBER working papers are circulated for discussion and comment purposes. They have not been peer-reviewed or been subject to the review by the NBER Board of Directors that accompanies official NBER publications.

(C) 2019 by Johannes Haushofer, Charlotte Ringdal, Jeremy P. Shapiro, and Xiao Yu Wang. All rights reserved. Short sections of text, not to exceed two paragraphs, may be quoted without explicit permission provided that full credit, including $\odot$ notice, is given to the source. 
Income Changes and Intimate Partner Violence: Evidence from Unconditional Cash Transfers in Kenya

Johannes Haushofer, Charlotte Ringdal, Jeremy P. Shapiro, and Xiao Yu Wang

NBER Working Paper No. 25627

March 2019, Revised July 2019

JEL No. C93,D13,O12

\begin{abstract}
In a previous study, we found an improvement in female empowerment after randomized unconditional cash transfers in Kenya (Haushofer and Shapiro 2016). Here we report detailed impacts of these transfers on physical and sexual intimate partner violence, and construct a theory to explain them. Transfers to women averaging USD 709 reduced physical and sexual violence (-0:26, -0:22 standard deviations). Transfers to men reduced physical violence (-0:18 SD). We find spillovers: physical violence towards non-recipient women in treatment villages decreased (-0:16 SD). We show theoretically that transfers to both men and women are needed to understand why violence occurs. Our theory suggests that husbands use physical violence to extract resources, but dislike it, while sexual violence is not used to extract resources, but is pleasurable.

Johannes Haushofer

Woodrow Wilson School

Princeton University

427 Peretsman-Scully Hall

Princeton, NJ 08540

and Busara Center for Behavioral Economics,

Nairobi, Kenya

and also NBER

haushofer@princeton.edu

Charlotte Ringdal

University of Amsterdam

Faculty of Economics and Business

Roetersstraat 11

Room \#E7.30

PO Box 15867

1001 NJ Amsterdam

c.ringdal@uva.nl

Jeremy P. Shapiro

Busara Center for Behavioral Economics

Daykio Plaza

Nairobi, Kenya

jeremy.shapiro@busaracenter.org

Xiao Yu Wang

Department of Economics

Duke University

213 Social Sciences Building

Box 90097

Durham, NC 27708

and NBER

xy.wang@duke.edu
\end{abstract}

A randomized controlled trials registry entry is available at https://www.socialscienceregistry.org/trials/19 


\section{Introduction}

Forty-two percent of women in Kenya aged 20-44 report having experienced physical or sexual violence from their current partner (Hindin, Kishor, and Ansara 2008). To design policies that effectively reduce the incidence of violence, we must first understand why it happens. How IPV responds to changes in economic variables for either partner can contribute to building this understanding. A previous study reported improvements in female empowerment following unconditional cash transfers in Kenya (Haushofer and Shapiro 2016). Here, we report additional results from this study, including detailed effects on physical and sexual IPV, and construct a theory to elucidate the underlying motives for IPV. ${ }^{1}$

Why do husbands engage in IPV? Existing literature distinguishes two motives, which may work independently or in concert: instrumental and expressive. Violence (threatened or realized) is said to be instrumental when it is used by husbands to extract resources from the wife to increase their own consumption (Tauchen, Witte, and Long 1991; Farmer and Tiefenthaler 1997; Eswaran and Malhotra 2011). ${ }^{2}$ In contrast, violence is expressive when it contributes directly to the husband's utility (Tauchen, Witte, and Long 1991). These non-pecuniary returns can be positive or negative: husbands may derive direct pleasure from engaging in violence, e.g. as a way assert dominance, or in the case of sexual violence. In such cases, violence is "expressively pleasurable". Conversely, husbands may find the use of violence displeasing, for example, because he cares for the wife, or because of stigma. Here,

\footnotetext{
${ }^{1}$ We focus on violence perpetrated by the husband against the wife because it accounts for the majority of violence, both in this context and in others. The previous paper used a gatekeeper strategy, i.e. it first tested effects of the program on a set of index variables, and then explored those indices in more detail that survived correction for multiple comparisons. We found significant effects on the female empowerment index in treatment compared to control villages, that survived correction for multiple comparisons across all index variables. In the original paper, this effect could not be explored further due to space constraints. This is the purpose of the present paper. Note that, like in the previous paper and as pre-specified in our PAP, we do not correct for multiple comparisons across variables within a family of outcomes.

${ }^{2}$ Some authors use the term "extractive" violence to refer specifically to the extraction of resources (Bloch and Rao 2002). This is a specific example of instrumental violence, which is a broader concept and can also include violence to control the wife's behavior and achieve control of decisions in the household (Hidrobo, Peterman, and Heise 2016). We focus on extractive instrumental violence because other types of instrumental violence can be expressed as extractive as long as transfers are possible.
} 
violence is "expressively distasteful". 3

In addition to the husband's motives, equilibrium violence is also determined by the wife's participation constraint. This constraint reflects the woman's outside option, which is affected endogenously by instrumental violence; and her "empowerment", a function that captures the effect of norms on a woman's disutility from violence. $^{4}$

How can we determine which motives are most salient in explaining equilibrium violence? In this paper, we present a theory which shows how income changes to both spouses can be used to make inferences about the motives underlying violence. Our framework allows all of the motives and channels described above to be at play: First, changes in income may (endogenously) affect the degree to which the husband extracts income from the wife. Second, changes in income may affect the degree to which the husband has a direct taste or distaste for violence. Finally, changes in income may affect the degree to which the wife tolerates violence instead of leaving the marriage. Tolerance reflects empowerment, both in the sense that the wife may not have enough resources to escape, and in the sense that she may view domestic violence as "normal".

Our main results show that studying the impact of cash transfers to the wife alone is insufficient for learning about the husband's motives for violence. In contrast, the sign of the impact on IPV of cash transfers to both the husband and the wife can be used to identify pecuniary and/or non-pecuniary returns to violence, i.e. whether violence is purely instrumental, purely expressive, both, or neither. Our empirical results show that unconditional cash transfers to the husband and to the wife

\footnotetext{
${ }^{3}$ Note that theories of "male backlash", which have been proposed in psychology, are also special cases of instrumental and expressive violence. Male backlash refers to cases where the husband engages in violence in response to an increase in (financial) empowerment of the wife (Tankard and Paluck 2016; Buller et al. 2018). If such "backlash violence" is used to extract income or otherwise force the spouse to conform to his preferences, it is instrumental; if it is used to restore his bruised ego without any economic consequences, it is expressive. In our theory, we allow for the former case, i.e. the possibility that the husband's preferred level of violence increases in the wife's income because it is more profitable to extract resources from a wealthier wife. However, this restriction is merely for convenience, and it would be straightforward to extend the theory to cover expressive backlash violence.

${ }^{4}$ Of course, norms may also affect the husband's (dis)utility from violence; this is captured in our expressive channel.
} 
both reduced violence. Using our theory, we infer that there are pecuniary and nonpecuniary returns to violence: specifically, IPV is instrumental, but the husband has a direct distaste for it. This result yields substantively different policy recommendations than, for example, a situation where IPV is not instrumental, but the husband derives direct pleasure from it. We also discuss how different types of violence (e.g., physical vs. sexual) may be differentially instrumental and expressive. In particular, our theory shows that our empirical results suggest that physical violence may be primarily instrumental, while sexual violence may be primarily expressive (pleasurable). These results suggest different policy approaches to reduce different types of violence.

Our second set of results considers the possibility of within-household transfers (to reduce confusion between our experimental transfers and the theoretical possibility of transfers between spouses, we refer to the former as "cash transfers" and the latter as "within-household transfers"). We show that, in a framework with feasible within-household transfers, the fact that violence exists in the status quo implies that violence must be expressively pleasurable for the husband (rather than expressively distasteful, as we conclude in the case of limited to no transfers). However, in such a case, it must be that transfers to the husband particularly lead to an increase in the husband's private consumption. Intuitively, when transfers are feasible, the husband always fully extracts surplus from the wife, because his utility is always strictly increasing in money extracted through non-violent means. Thus, the wife's participation constraint defines an indifference curve over bundles of violence and transfers: lower levels of violence necessarily correspond to higher transfers. Hence, the husband's consumption must rise if violence falls following a transfer to the husband. However, empirically, we observe no effect on husband's consumption. Thus, we infer that within-household transfers play a limited role in our context.

Our third set of results describes how the relative magnitudes of the impact of transfers to the wife versus the husband shed light on whether violence is more effectively reduced by decreasing the husband's demand for it, or by decreasing the wife's tolerance of it. For example, we show that if a transfer to the wife reduces IPV by more than an equivalent transfer to the husband, then the dominant factors determining violence in the status quo are related to women's resources and empowerment, i.e. a combination of women lacking the financial and psychological 
ability to leave violent marriages. Thus, policy that targeted these areas might be more effective than policies that focus on making husbands better off. Finally, we sketch an extension of our model which allows for spillovers of reductions in domestic violence to neighboring households through social norms.

Our empirical evidence on the effect of income changes on IPV comes from a randomized controlled trial on unconditional cash transfers with about 1500 households in western Kenya. Effects of the program on economic and psychological wellbeing variables have already been reported in a previous paper (Haushofer and Shapiro 2016). That paper also included reduced-form impacts on a female empowerment index, which was a standardized weighted average of a group of variables which included indices of physical and sexual violence. In the present paper we report the detailed impacts that were previously summarized in this index. Between 2011 and 2013, the NGO GiveDirectly, Inc. made unconditional cash transfers of, on average, USD 709 PPP, corresponding to about two years of per capita expenditure, to households in western Kenya using the mobile money system M-Pesa. Recipients were chosen for meeting a basic means test criterion, did not expect the transfers, and were explicitly informed that they were unconditional. We randomized at the village level, the household level within villages, and whether transfers were sent to the man or the woman in the household. ${ }^{5}$

In female recipient households, transfers led to a significant reduction in both physical (0.26 SD) and sexual (0.22 SD) violence. Women in male recipient households report a statistically significant $0.18 \mathrm{SD}$ reduction in physical violence. In contrast, sexual violence was not significantly reduced when the husband received money. ${ }^{6}$ Together with our theory, these results suggest that violence is used instrumentally, but that physical violence is expressively distasteful; sexual violence, however, may be expressively pleasurable. Our results further suggest that transfers

\footnotetext{
${ }^{5}$ Additional randomization arms were the magnitude of the transfer (USD 404 PPP vs. USD $1525 \mathrm{PPP}$ ) and the timing of the transfer (lump-sum transfer vs. nine monthly installments); however, in this paper, we focus on the randomization of recipient gender.

${ }^{6}$ Social desirability bias or reciprocity is unlikely to account for the improvements in treatment households because participants were informed by the survey team that the survey was independent of the intervention. Participants thus had no incentive to deceive field officers. The fact that several important outcomes, such as health and education, did not show treatment effects suggests that social desirability bias or reciprocity motives did not play an important role.
} 
to the wife primarily reduce IPV by reducing her tolerance of it, while transfers to the husband reduce IPV by reducing his marginal taste for it.

A further unresolved question about the effect of cash transfers on domestic violence is whether they affect not only recipient, but also non-recipient households. In standard economic models, such spillovers would only occur in the presence of economic spillovers. In contrast, social norms may respond to cash transfers in both recipient and non-recipient households even in the absence of economic spillovers. If IPV is reduced in recipient households due to improvements in the wife's bargaining power or her outside option (Almås et al. 2018), this reduction might translate into a change in the perceived prevalence and/or perceived justifiability of IPV. ${ }^{7}$ If non-recipients are motivated to conform to these norms, we might expect a change in IPV even in non-recipient households and in the absence of economic spillovers.

Our two-stage randomization design allows us to study the spillovers of transfers on non-recipients in the same villages by comparing "spillover" to "pure control" households. Non-recipient women in treatment villages show an increase of 0.19 $\mathrm{SD}$ in the female empowerment index, driven by a $0.16 \mathrm{SD}$ reduction in physical violence, although no significant reduction in sexual violence $(-0.11 \mathrm{SD})$. These findings suggest that the reduction of IPV through cash transfers in recipient households may lead to a change in social norms. In line with this hypothesis, women in both treatment and spillover households are somewhat less likely to view IPV as permissible, although these effects are weak and only statistically significant for a small subset of outcome variables, and not for a norms index. ${ }^{8}$

\footnotetext{
${ }^{7}$ In social psychology, perceived prevalence is referred to as descriptive norm, while perceived justifiability is referred to as prescriptive norm (Tankard and Paluck 2016).

${ }^{8}$ One concern with these spillover findings is that treatment and spillover households were surveyed twice, while pure control households were surveyed once. It is possible that being surveyed at baseline raised awareness of domestic violence in treatment and spillover households, and led to a change in its incidence simply for this reason, and independently of the cash transfer (Zwane et al. 2011). To rule out this possibility, we conducted a separate "survey effects" experiment, in which we asked whether a survey in the absence of any other treatment reduces subsequent reports of IPV. Specifically, we re-administered the same survey to the pure control group two years after the initial endline survey, and additionally administered the survey to a new sample of 500 households, randomly chosen from the same population, at the same time. Because neither group receive any interventions other than the survey, this design allows us to estimate the effects of the initial survey in the pure control group on responses in the second administration of that same survey. We find no evidence of survey effects; the coefficients are economically small and statistically insignificant.
} 
This study contributes to a growing empirical literature on the effect of economic variables on IPV. The evidence on the effects of economic changes that mainly affect women on IPV is mixed: Previous studies have shown that improved outside options for women due to changes in divorce laws (Stevenson and Wolfers 2006) or reductions in the wage gap (Aizer 2010) lead to lower levels of violence against women. Several studies of the Oportunidades program, which made conditional cash transfers to women in Mexico, have found reductions in domestic violence against women in beneficiary households (Angelucci 2008; Bobonis, Gonzalez-Brenes, and Castro 2013). Similarly, Hidrobo and Fernald (2013) and Hidrobo, Peterman, and Heise (2016) show that transfers of cash and food significantly reduce physical and emotional violence against women in Ecuador. On the other hand, a study in Bangladesh found that cash transfers only reduced violence when combined with behavior change communication (Roy et al. 2018). In addition, women may receive more non-violent threats from their partners as a result of participating in Oportunidades (Bobonis 2009), and large cash transfers may increase violence perpetrated by men with traditional views on gender roles (Angelucci 2008). Relatedly, Tankard (2016) finds that an economic empowerment program for women in Colombia leads to an increase in IPV among women who experienced baseline IPV. Our study contributes an additional datapoint to these disparate findings. In addition, previous studies have not directly estimated the empirical effect of income changes of the husband on IPV. Heath, Hidrobo, and Roy (2018) study Mali's national cash transfer program to heads of households, most of whom are men, but their focus is on comparing the impact on IPV in polygamous vs. non-polygamous households. Our study builds on this work by directly estimating and comparing the effect of cash transfers to the husband and the wife. We then use both of these estimates to identify underlying motives of violence, which is key for guiding policy design in our context.

Our study further contributes to the theoretical literature on IPV. A number of models of intimate partner violence have been proposed, and between them, they describe many of the mechanisms which we discuss in this paper: When the wife's income increases, violence may decrease if the extra income improves the wife's outside option or otherwise raises her participation constraint in the marriage (Tauchen, Witte, and Long 1991; Farmer and Tiefenthaler 1997; Eswaran and 
Malhotra 2011; see also Buller et al. 2018). ${ }^{9}$ Conversely, violence may increase if the husband wants to extract some of the additional income from her or otherwise align outcomes with his preferences (Tauchen, Witte, and Long 1991; Eswaran and Malhotra 2011; see also Tankard 2016). ${ }^{10}$ When the husband's income increases, violence may increase if the husband derives utility from it and now can "afford" more of it (Tauchen, Witte, and Long 1991; Farmer and Tiefenthaler 1997; Eswaran and Malhotra 2011). Conversely, violence may decrease if the husband dislikes violence (Eswaran and Malhotra 2011) or if transfers to the husband improve the wife's outside option (e.g. through divorce settlements; Farmer and Tiefenthaler 1997).

However, the existing models study each of these possible motives for violence in partial isolation. By contrast, we model all of these motives in a single framework. Specifically, we allow violence to be either expressively pleasurable, which is how Tauchen, Witte, and Long (1991) and Farmer and Tiefenthaler (1997) model it; or expressively distasteful, which is how Eswaran and Malhotra (2011) conceive of it. Similarly, we allow for instrumental violence, which e.g. Farmer and Tiefenthaler (1997) do not. Thus, we nest the other models as special cases and allow for multiple motives to operate and interact in explaining the incidence of violence.

The remainder of this paper is structured as follows. Section 2 presents the theoretical model. Section 3 describes the intervention, the experimental design, and the econometric approach. Section 4 presents the impacts of the program on IPV and related outcomes. Section 5 concludes.

\footnotetext{
${ }^{9}$ Buller et al. (2018) present a thorough review of the evidence on the effect of cash transfers on IPV, and propose three mechanisms by which cash transfers may affect violence: first, they may improve economic security, e.g. in terms of food security, and thereby lead to an increase in emotional well-being which then reduces IPV. Second, they may increase the availability of cash to meet daily needs, and thereby reduce conflict in the relationship; but also possibly increase conflict due to increased availability of money for temptation goods. Finally, they may lead to empowerment of women, e.g. through financial autonomy or increased self-confidence, which may reduce violence, but can also lead to backlash. As will become clear below, all of these mechanisms can be accommodated in our framework.

${ }^{10}$ Less directly related is the model of Bloch and Rao (2002), in which the husband can use violence to extract money from the wife's family rather than the wife herself; and that of Pollak (2004), who models the intergenerational transmission of violence without particular attention to whether it is used instrumentally vs. expressively.
} 


\section{Theoretical framework}

\subsection{General set-up}

Consider a one-period, two-person household in which husband $(H)$ and wife $(W)$ earn separate, exogenously-given incomes, $y_{H}$ and $y_{W} \cdot{ }^{11}$ Both spouses have increasing and concave utility functions, $u_{H}(c)$ and $u_{W}(\mathrm{c})$. In addition to private consumption, each may also derive (dis)utility from violence. This (dis)utility can be pecuniary, through the effects of violence on consumption, and/or non-pecuniary. Let $f\left(v, y_{W}\right)$ capture the pecuniary, or "instrumental" motive for violence. ${ }^{12}$ This function describes how much income a husband using violence level $v$ extracts from a wife with income $y_{W}$. The dependence of $f\left(v, y_{W}\right)$ on $v$ captures the instrumentality of violence. Violence is "instrumental" if $f_{v}>0$ and "not instrumental" if $f_{v}=0 .{ }^{13}$ We make no assumption about $f_{v y_{W}}$.

Second, domestic violence can be expressive, i.e. $H$ may derive direct (dis)utility from violence (non-pecuniary returns). Let $g\left(v, y_{H}\right)$ denote the husband's (dis)utility from IPV. When $g_{v}>0$, we say that violence is expressively pleasurable: the husband derives more direct utility from higher levels of violence. Conversely, when $g_{v}<0$, violence is expressively distasteful: the husband derives less direct utility from higher levels of violence. If $g_{v}=0$, we say that violence is not expressive. ${ }^{14}$ We make no assumption about $g_{v y_{H}}$.

The wife derives disutility from violence, both directly and indirectly through the reduction in her consumption if violence is used to extract her resources. Let

\footnotetext{
${ }^{11}$ We study exogenous incomes since our experiment gives unconditional cash transfers to $H$ and $W$.

${ }^{12}$ Let $f\left(v, y_{W}\right)$ be continuous in both its arguments, and $f\left(v, y_{W}\right) \leq y_{W}, f\left(0, y_{W}\right)=0$, and $f(v, 0)=0$.

${ }^{13}$ For clarity in distinguishing "instrumental" from "non-instrumental" violence, it is easiest to think of $f\left(v, y_{W}\right)$ as monotonically increasing or flat in $v$. However, the same intuition applies when $f$ is locally monotonic. For example, it could be that $f\left(v, y_{W}\right)$ is increasing over $v<\bar{v}$, and not after - then violence is instrumental up to the point $\bar{v}$, otherwise not instrumental, and our results still apply. We can also allow for $f_{v}<0$ over some interval, but we exclude $f\left(v, y_{w}\right)$ monotonically decreasing in $v$ on the grounds that it appears implausible that no violence is much more extractive than some violence. We do consider the possibility of non-violent within-household transfers in 2.3.

${ }^{14}$ As with $f$, note that local monotonicity is sufficient, e.g. violence is expressively pleasurable if $g\left(v, y_{H}\right)$ is increasing in $v$ in the neighborhood around the status quo level of violence.
} 
$h\left(v, y_{W}\right)$ describe the wife's direct, non-pecuniary disutility from violence, where $h\left(0, y_{W}\right)=0$. In contrast to $g\left(v, y_{H}\right), h\left(v, y_{W}\right)$ is always increasing in violence $v$. We make no assumption about $h_{v y_{W}}$. Let $\bar{u}_{W}\left(y_{W} ; v\right)$ denote the wife's outside option, where $\bar{u}_{W}\left(y_{W} ; v\right)$ decreases in $v$, and $\bar{u}_{W}\left(y_{W}\right) \leq u_{W}\left(y_{W}\right)$ so that her participation constraint, $P_{W}$, is satisfied when there is no violence.

Then, the equilibrium level of violence solves the following program: ${ }^{15}$

$$
\begin{aligned}
& \max _{v \geq 0} u_{H}\left(y_{H}+f\left(v, y_{W}\right)\right)+g\left(v, y_{H}\right) \\
& \text { s.t.P. } P_{W}: u_{W}\left(y_{W}-f\left(v, y_{W}\right)\right)-h\left(v, y_{W}\right) \geq \bar{u}_{W}\left(y_{W} ; v\right)
\end{aligned}
$$

Crucially, observe that the wife's participation constraint $P_{W}$ does not necessarily bind in equilibrium. For example, suppose that the husband has a strong distaste for violence $\left(g^{\prime}(v)<0\right)$. Then his unconstrained choice of violence may be lower than the level that binds $P_{W}$. However, if the husband derives pleasure from violence $\left(g^{\prime}(v) \geq 0\right)$, then $P_{W}$ always binds in equilibrium because he exerts as much violence as the wife will tolerate without leaving. Notationally, we denote the husband's unconstrained choice of violence $v^{H}$, and the maximal level of violence the woman tolerates before leaving the marriage, $v^{W}$ (this is the level that binds $P_{W}$ ).

The framework can also accommodate more nuanced motives for violence. One such motive is stress, which our framework captures if $v$ and $y_{h}$ are weak substitutes in the expressive, non-pecuniary term $g\left(v, y_{H}\right)$. This causes $v$ and $y_{h}$ to be weak substitutes in the husband's total utility (the maximand), as a consequence of diminishing marginal returns to consumption. ${ }^{16}$ Thus, poorer men, who are more stressed, get higher marginal utility from violence. This captures the idea from existing literature that the husband may use violence to release stress, e.g. from having a low income. In contrast, a wealthier husband may derive less marginal pleasure from violence because he is less stressed. Conversely, if $v$ and $y_{H}$ are strong complements in the husband's expressive, non-pecuniary term, then $v$ and

\footnotetext{
${ }^{15}$ As is customary, we assume conditions for the existence of a unique interior solution. For example, $f_{v v} \geq 0, g_{v v} \leq 0$, and $h_{v v} \geq 0$ are sufficient.

$16 \frac{\partial\left[u_{H}\left(y_{H}+f\left(v, y_{W}\right)\right)+g\left(v, y_{H}\right)\right]}{\partial v \partial y_{H}}=u_{H}^{\prime \prime} f_{v}+g_{v y_{H}}<0$ if $g_{v y_{H}} \leq 0$.
} 
$y_{H}$ will be complements in the husband's total utility, capturing the possibility that wealthier husbands derive greater pleasure from violence. These are just a few additional channels that our framework can accommodate, even though we explicitly model only the basic instrumental and expressive channels.

In our benchmark model, we do not allow for within-household transfers. We extend the theory to allow for this possibility in Section 2.3.

\subsection{Determining the underlying motives for violence}

Our main results show how the responses of violence to cash transfers to both the husband and the wife enable us to identify and distinguish the motives underlying equilibrium violence.

First, we observe that cash transfers to the wife alone are insufficient for determining whether violence is purely instrumental, purely pleasurable, instrumental and pleasurable, or instrumental and distasteful.

Result 1. (a) An increase in IPV following cash transfers to the wife is consistent with violence being purely instrumental, purely pleasurable, instrumental and pleasurable, and instrumental and distasteful.

(b) A decrease in IPV following cash transfers to the wife is consistent with violence being purely instrumental, purely pleasurable, instrumental and pleasurable, and instrumental and distasteful.

First suppose that cash transfers to the wife increase IPV. Cash transfers could relax her participation constraint (e.g. because her consumption within the marriage is higher at the original level of violence). Then violence may be purely pleasurable - the husband is able to use more violence without violating the participation constraint. Violence may also be purely instrumental - the wife becomes a more valuable target for extraction. Clearly, violence may also be instrumental and pleasurable, or instrumental and distasteful, as long as the marginal gains from extraction outweigh the marginal direct disutility from violence.

Now suppose that cash transfers to the wife decrease IPV. Cash transfers could tighten her participation constraint (for example, because she is more empowered, both literally and in terms of norms, and receives greater disutility from experi- 
encing violence). Even if violence is purely pleasurable, the husband must decrease $v$ in order to satisfy the wife's participation constraint. The same is true if violence is purely instrumental, or instrumental and pleasurable. If violence is instrumental and distasteful, it could be the woman's tightened participation constraint that causes equilibrium violence to fall, or it could be that the marginal distaste cost now outweighs the marginal gains from extraction for the husband, if a given level of violence extracts more money from a wealthier wife.

The crucial insight from the preceding discussion is that transfers to the wife, regardless of how they affect violence, do not allow us to determine the motives underlying violence. Our main contribution, described next, is to show that transfers to the husband do allow us to gain such insights. In describing how transfers to the husband can be used to make inferences about the motives for violence, we foreshadow our empirical results to some extent, because they narrow down the set of possible motives. They are presented in detail in Section 4.

We immediately rule out the case where violence is neither instrumental nor expressive $\left(f_{v}=0\right.$ and $\left.g_{v}=0\right)$, because then we should never observe violence in the status quo. This is inconsistent with baseline and control group levels of violence, which are high (cf. Section 4). This leaves four cases: (i) violence is instrumental and weakly expressively pleasurable, $f_{v}>0, g_{v} \geq 0$; (ii) violence is not instrumental and is expressively pleasurable, $f_{v}=0, g_{v}>0$; (iii) violence is not instrumental and is expressively distasteful, $f_{v}=0, g_{v}<0$; and (iv) violence is instrumental and expressively distasteful: $f_{v}>0, g_{v}<0$.

Result 2. If violence is weakly expressively pleasurable ( $g_{v} \geq 0$; cases (i) and (ii)), then a cash transfer to the husband has no effect on the equilibrium level of violence.

If the husband derives pleasure from violence, transfers to him cannot affect violence in equilibrium. If $g^{\prime}(v) \geq 0$, then $H$ 's total utility is strictly increasing in $v$ (because either $g_{v}>0$ and $f_{v} \geq 0$, or $g_{v}=0$ and $f_{v}>0$ ). Intuitively, if the husband's utility is higher the more violence he uses, then he is already exerting as much violence as the wife will tolerate in the status quo, and giving him money will not affect this. More precisely, violence in the status quo is disciplined only by the wife's maximal tolerance. That is, $v^{*}=v^{W}$, the level that makes $W$ exactly indifferent between staying and leaving. But the wife's participation constraint does not depend 
directly on $y_{H}\left(y_{H}\right.$ only enters indirectly, through its effect on $\left.v^{*}\right)$. Thus, a cash transfer to the husband does not change $v^{W}$, and by implication, does not change $v^{*}$.

What happens if $y_{H}$ does change the wife's participation constraint, for example, because within-household transfers are feasible, or because a portion of the increase in $y_{H}$ accrues to the wife through some process? We explicitly consider withinhousehold transfers in 2.3 and show that violence increases because the husband will use his cash transfer to buy more violence from his wife. If the wife captures some of $y_{H}$, and this tightens her participation constraint, a strictly violence-loving husband will respond by increasing violence to decrease her outside option. Thus, these extensions all suggest that if $g_{v} \geq 0$, a cash transfer to the husband will increase IPV.

Given that we find empirically that cash transfers to $H$ do have an effect on violence, in fact, they decrease violence, we rule out $g_{v} \geq 0$. That is, husbands appear to find violence distasteful: $g_{v}<0$.

Given that $g_{v}<0$, what can we then infer about the instrumentality of violence?

Result 3. If violence is expressively distasteful $\left(g_{v}<0\right)$ and not instrumental $\left(f_{v}=0\right)$, then $v^{*}=0$, i.e. $H$ never chooses positive levels of violence.

If violence is distasteful but not instrumental, then $H$ 's utility is strictly decreasing in violence. But then we should never observe violence. Since we do observe non-zero levels of violence in the control group and at baseline, we must conclude that violence, while distasteful, enables $H$ to extract some income from $W$, which increases his utility by increasing his consumption.

In light of Results 2 and 3, we conclude that, in our setting, $f_{v}>0$ and $g_{v}<0$ : violence is instrumental and expressively distasteful. In other words, the pecuniary returns are positive, but the non-pecuniary returns are negative.

These results are summarized in Table C1, which describes the effect of a cash transfer to the husband on equilibrium violence for each of our cases.

It is important to note that these results do not suggest that we do not need to study the impact of cash transfers to the wife on IPV. Rather, the point is that we need both. While the effect of cash transfers to the husband is critical for understanding the instrumental vs. expressive channels, the wife's participation constraint is an essential determinant of equilibrium violence and thus a key piece of the policy puzzle. For example, cash transfers to the husband tell us that 
in our setting, violence is both instrumental and expressively distasteful. This helpfully rules out policies that would make sense if violence were purely pleasurable. However, as $\mathrm{C} 1$ shows, in this case, cash transfers to the husband can theoretically increase or decrease IPV. So, why did our experiment result in a decrease?

To understand this, we must turn to the impact of cash transfers to the wife.

Result 4. A cash transfer to the wife decreases equilibrium violence if violence and wife's income are complements in the wife's disutility from violence $\left(h_{v y_{W}}>0\right)$, the wife's outside option is convex in her resources, and violence and wife's income are weak complements in the extractive technology (i.e. $f_{v y_{w}}>0$ ).

Note that this is a sufficient, but not necessary set of conditions; it is possible for a cash transfer to the wife to decrease equilibrium violence even if some of these conditions do not hold.

The intuition is as follows. A transfer to the wife reduces her maximallytolerated violence if the increase in her income exposes her to norms that are less tolerant of IPV, or empowers her to feel less tolerant of IPV, or gives her more resources to leave a bad marriage. Moreover, if an additional "unit" of violence yields a much higher pecuniary return when the wife is wealthier, then the husband does not need to use as much violence to extract the same level of consumption. Since the husband has both a distaste for violence and diminishing marginal returns to consumption, this puts downward pressure on the level of violence he prefers to use.

If we had instead observed that a transfer to the wife increased IPV, then that would tell us that in this context, cash infusions to the wife do not empower her or increase her ability to leave bad marriages. Rather, they are co-opted by the husband and/or only serve to make her a more valuable target for extraction, which would be essential to know for policy design. We discuss this possibility further in 2.3.

Finally, observe that the husband's underlying motives for different "types" of violence may be different, so that it may be important to study distinct types of violent behavior, rather than looking only at "pooled" violence. For example, we find empirically that a cash transfer to the wife decreases both physical and sexual violence, while a cash transfer to the husband decreases only physical violence and has no effect on sexual violence (see Section 4). Using our Result 2, we conclude that $g_{v_{\text {physical }}<0}$ but $g_{v_{\text {sexual }}}>0$ : the husband derives expressive distaste from physical 
violence, but expressive pleasure from sexual violence. In addition, physical violence is likely more extractive of consumption than sexual violence; this is why the husband reduces his use of physical violence following a cash infusion, but not his use of sexual violence. Why does a cash transfer to the wife reduce both types of violence? Using our Result 4, we conclude that the cash transfer to the wife tightens her participation constraint by empowering her to reject both types of violence, and/or by increasing her resources to escape a violent marriage. Hence, in our context, physical violence may be primarily instrumental, while sexual violence may be primarily expressive. To reduce the former, cash transfers to the husband may be more effective, while cash transfers to the wife may be more effective at reducing the latter.

Appendix A3 presents a numerical example and a graphical representation of the benchmark model. Appendix A also presents additional results describing what we can further learn about the underlying motives of violence by examining not only the signs, but the relative magnitudes of the impact of cash transfers to the wife and the husband on IPV.

\subsection{Within-household transfers}

In our benchmark model, we have abstracted away from the possibility of withinhousehold transfers. But what if, in addition to a level of violence, the husband and wife can also "agree" on a feasible transfer between themselves? Existing models of household decision-making often allow for transfers; we therefore modify our benchmark model to allow for transfers $t$ from the wife to the husband. The maximization program is now:

$$
\begin{aligned}
& \max _{v \geq 0, t} u_{H}\left(y_{H}+f\left(v, y_{W}\right)+t\right)+g\left(v, y_{H}\right) \text { s.t. } \\
& P_{W}: u_{W}\left(y_{W}-f\left(v, y_{W}\right)-t\right)-h\left(v, y_{W}\right) \geq \bar{u}\left(y_{W}-f\left(v, y_{W}\right)-t\right) \\
& \quad t \in\left[-y_{H}, y_{W}\right]
\end{aligned}
$$

Let the wife's outside option be $\bar{u}_{W}\left(y_{W} ; v\right)=r u_{W}\left(y_{W} ; v\right), r \in(0,1)$. This reflects the extra cost of using resources to escape a bad marriage, rather than simply consuming the resources and staying. 
Note that this is a cooperative model and that the outcome will be Paretoefficient.

Lemma 1. The wife's participation constraint always binds when withinhousehold transfers are feasible.

Observe that $H$ 's utility is strictly increasing in $t$, while $W$ 's utility is strictly decreasing in $t$. Essentially, the husband always likes money he can receive frictionlessly. Clearly, $v=0$ and $t=y_{W}$ always binds $P_{W}$. Thus, $H$ will always fully extract surplus using $t$. The worst he can do (from the point of view of the wife's welfare) is to consume both $y_{H}$ and $y_{W}$ and use no violence.

Given this, rearrange the binding $P_{W}$ to express the within-household transfer $t$ in terms of $v$ :

$$
u_{W}\left(y_{W}-f\left(v, y_{W}\right)-t\right)=\frac{h\left(v, y_{W}\right)}{1-r}
$$

Because $u(c)$ is strictly increasing and continuous, it is invertible. Moreover, since $u_{c}>0$, it follows that $u_{c}^{-1}>0$. Thus:

$$
t(v)=y_{W}-f\left(v, y_{W}\right)-u_{W}^{-1}\left(\frac{h\left(v, y_{W}\right)}{1-r}\right)
$$

Substituting this expression into the maximand yields:

$$
\max _{v \geq 0} u_{H}\left[y_{H}+y_{W}-u_{W}^{-1}\left(\frac{h\left(v, y_{W}\right)}{1-r}\right)\right]+g\left(v, y_{H}\right)
$$

Notationally, call this maximand $U_{H}\left(v ; y_{H}, y_{W}\right)=u_{H}\left[y_{H}+y_{W}-u_{W}^{-1}\left(\frac{h\left(v, y_{W}\right)}{1-r}\right)\right]+$ $g\left(v, y_{H}\right)$

We obtain the following results.

Result 5. If violence is expressively distasteful $\left(g_{v}<0\right)$, then there is no violence in equilibrium, and spousal income changes do not affect violence.

If $g_{v}<0, U_{H}$ clearly decreases in $v$. Intuitively, if violence is expressively distasteful for $H$, then the husband will always "extract" consumption from the wife non-violently, via within-household transfers; this is cheaper for him than extraction through violence. The wife "agrees" to transfer the husband the money, 
because $t=y_{W}$ and $v=0$ satisfies $P_{W} \cdot{ }^{17}$

Thus, if within-household transfers are at play, our empirical finding that a cash transfer to the husband reduced IPV rules out violence being expressively distasteful, in stark contrast with our benchmark model.

Result 6. There exists a positive constant $c$ such that, if $g_{v}>>c$, then cash transfers to the husband increase violence.

If $g_{v}>>c$, then $U_{H}$ increases in $v$. In other words, $H$ 's marginal utility from $v$ (which yields pecuniary benefits through extraction, as well as the non-pecuniary benefit of pleasure) is greater than his utility from increasing consumption $c$ nonviolently $\left(u_{H}^{\prime}(c)\right)$. In this case, he uses all of his money to "buy violence" from the wife: $t=-y_{H}$, and $v$ satisfies $y_{H}+y_{W}=f\left(v, y_{W}\right)+u^{-1}\left(\frac{h\left(v, y_{W}\right)}{1-r}\right)$. (This is the maximal level of violence $H$ can use without violating $P_{W}$.) Clearly, the only constraint to violence in equilibrium is how much $H$ can afford. If he receives a cash transfer, then $y_{H}$ rises and he can afford more violence, so violence increases.

This contradicts our empirical findings, so we can rule this case out.

Result 7. Suppose $g_{v}>0$ for $v<\tilde{v}$, while $g_{v} \leq 0$ for $v \geq \tilde{v}$; i.e., violence is expressively pleasurable up to some level of violence, and thereafter weakly expressively distasteful. Then:

(a) A cash transfer to $H$ decreases violence iff $g_{v y_{H}}<0$.

(b) A cash transfer to $W$ decreases violence iff $h_{v y_{W}}>0$.

For ease of notation, denote the consumption of $H$ and $W$ as:

$$
\begin{aligned}
& c_{H} \equiv y_{H}+y_{W}-u_{W}^{-1}\left(\frac{h\left(v, y_{W}\right)}{1-r}\right) \\
& c_{W} \equiv u_{W}^{-1}\left(\frac{h\left(v, y_{W}\right)}{1-r}\right)
\end{aligned}
$$

Then the (necessary and sufficient) first-order condition with respect to $v$ is:

$$
F O C_{v}:-\frac{1}{1-r} \frac{\partial u_{H}}{\partial c}\left(c_{H}\right) \frac{\partial u_{W}^{-1}}{\partial c}\left(\frac{h\left(v, y_{W}\right)}{1-r}\right) \frac{\partial h}{\partial v}\left(v, y_{W}\right)+\frac{\partial g}{\partial v}\left(v, y_{H}\right)=0
$$

\footnotetext{
${ }^{17}$ Note that it is not the case that the wife has no bargaining power; her outside option is her threat point.
} 
Remark. Since the first term is clearly negative, this implies that $\frac{\partial g}{\partial v}\left(v^{*}, y_{H}\right)>0$. Because $\left(u^{-1}\right)^{\prime}(a)=\frac{1}{u^{\prime}\left(u^{-1}(a)\right)}$, we can rewrite $F O C_{v}$ as:

$$
\frac{1}{1-r} \frac{\frac{\partial u_{H}}{\partial c}\left(c_{H}\right)}{\frac{\partial u_{W}}{\partial c}\left(c_{W}\right)}=\frac{\frac{\partial g}{\partial v}\left(v, y_{H}\right)}{\frac{\partial h}{\partial v}\left(v, y_{W}\right)}
$$

What happens when $y_{H}$ increases?

If $\frac{\partial g}{\partial v \partial y_{H}}>0$, then an increase in $y_{H}$ means the numerator is bigger at the original level of violence $\left(\frac{\partial g}{\partial v}\left(v^{\text {pre }}, y_{H}^{p o s t}\right)>\frac{\partial g}{\partial v}\left(v^{p r e}, y_{H}^{\text {pre }}\right)\right)$. To countervail this, $v$ needs to move to increase the denominator. Since $h$ is increasing and convex in $v$, this means $v$ increases.

If $\frac{\partial g}{\partial v \partial y_{H}}<0$, then an increase in $y_{H}$ means the numerator is smaller at the original level of violence $\left(\frac{\partial g}{\partial v}\left(v^{\text {pre }}, y_{H}^{\text {post }}\right)<\frac{\partial g}{\partial v}\left(v^{\text {pre }}, y_{H}^{\text {pre }}\right)\right)$. To countervail this, $v$ needs to move to decrease the denominator. Since $h$ is convex and increasing, this means $v$ decreases.

What happens when $y_{W}$ increases?

If $\frac{\partial h}{\partial v \partial y_{W}}>0$, then an increase in $y_{W}$ means the denominator is bigger at the original level of violence $\left(\frac{\partial h}{\partial v}\left(v^{p r e}, y_{W}^{\text {post }}\right)>\frac{\partial h}{\partial v}\left(v^{\text {pre }}, y_{H}^{\text {pre }}\right)\right)$. Thus, $v$ needs to respond to make the numerator bigger, too. Since $g$ is concave, and we know that $\frac{\partial g}{\partial v}\left(v^{p r e}, y_{H}\right)>0$ (by the Remark), this means that $v$ must decrease.

If $\frac{\partial h}{\partial v \partial y_{W}}<0$, the analogous logic implies that $v$ must increase.

Thus, our analysis so far implies that, if within-household transfers are feasible, it must be the case that violence is initially pleasurable, but then becomes distasteful at high levels. Violence may or may not be instrumental.

Since these are very different conclusions than those we reached under our benchmark model with no within-household transfers, we look to more of our empirical evidence to help us identify which world we are in.

\subsubsection{The impact of an increase in $y_{H}$ and $y_{W}$ on individual consump- tion}

What predictions does our theory generate about the impact of cash transfers on private consumption patterns of $H$ and $W$, when conditions are such that cash 
transfers to both spouses reduce IPV?

Result 8. (a) When within-household transfers are feasible, and conditions are such that cash transfers to both spouses reduce IPV, cash transfers to both spouses reduce $W$ 's consumption, and increase $H$ 's consumption.

(b) When within-household transfers are not feasible, and conditions are such that cash transfers to both spouses reduce IPV, a cash transfer to $W$ increases $W$ 's consumption by more than it increases $H$ 's consumption. A cash transfer to $H$ increases H's consumption, but by less than the amount of the transfer, and also increases $W$ 's consumption.

Intuitively, (a) is true because, when within-household transfers are feasible, the husband always uses such a transfer to fully extract surplus from $W$. (Recall that taking money away from $W$ not only reduces her consumption, it also reduces her outside option.) Thus, $P_{W}$ defines an indifference curve of bundles of violence and transfers $(v, t(v)): W$ is indifferent between lower transfers and higher violence, and higher transfers and lower violence. Therefore, if a policy causes a reduction in the use of violence, it necessarily must also cause an increase in the within-household transfer that $W$ makes to $H$. This increase in within-household transfers exactly countervails the reduction in violence and keeps her on the same indifference curve. However, as we show below, we observe an increase in the wife's private consumption after transfers to both her and the husband. This fact is thus not consistent with a model in which within-household transfers are important.

In contrast, in the model in which within-household transfers are not feasible, transfer to either $y_{W}$ or $y_{H}$ which reduce violence partially accrue to the wife. This is precisely because violence is the husband's only method of extracting resources from $W$ in this model. We have shown that a cash transfer to $H$ can only reduce IPV when violence is a costly (distasteful) method of extraction (unlike a frictionless within-household transfer). Thus, when violence is reduced under these conditions, $W$ 's consumption can actually go up. When the cash transfer is to $H$, diminishing marginal returns to consumption and distasteful violence imply that he reduces the use of violence. Thus, his consumption increases by less than the amount of the transfer (because he reduces his extraction). The reduced extraction increases $W$ 's consumption. When the cash transfer is to $W$, the increase in her empowerment 
and the fact that violence is a costly method of extraction for $H$ leads to an increase in her consumption that outweighs the increase in his. Thus, the model without within-household transfers is consistent with an increase in her private consumption, which we empirically observe.

Together, we view these considerations as evidence that within-household transfers play a limited or no role, and our benchmark model is a good approximation of our setting.

\subsection{Spillovers and Norms}

In the following we describe a simple mechanism based on social norms that would produce spillovers for untreated households. Assume that the direct utility of IPV for the husband can be decomposed into two terms. The first term is the (dis)utility term $g(v)$ discussed above. The second term reflects social norms. For simplicity, we model the norm as the average level of domestic violence in the village, $\bar{v}$. Any deviation from the social norm creates a disutility for the husband (for example, through stigma from non-conformity). Let the husband's utility be given by:

$$
u_{H}(c)+g(v)-(v-\bar{v})^{2}
$$

where $\bar{v}$ denotes the average level of IPV in the village. We square the disutility term to allow for disutility both when the husband engages in more violence than is the norm, but also when he engages in less violence.

The constraints are the same as mentioned above. The husband's maximization problem can then be written as:

$$
\begin{aligned}
& \max _{v \geq 0} u_{H}\left(y_{H}+f\left(v, y_{W}\right)\right)+g\left(v, y_{H}\right)-(v-\bar{v})^{2} \\
& \text { s.t. } P_{W}: u_{W}\left(y_{W}-f\left(v, y_{W}\right)\right)-h\left(v, y_{W}\right) \geq \quad \bar{u}_{W}\left(y_{W} ; v\right)
\end{aligned}
$$

It is straightforward to see that a decrease in the average level of domestic violence in a village from $\bar{v}$ to $\bar{v}^{\prime}<\bar{v}$ decreases violence in a given household. If $v>\bar{v}$, a decrease in $\bar{v}$ makes the deviation from the social norm more painful, and thus $H$ 's 
preferred level of violence, $v^{H}$, decreases. If $v<\bar{v}, H$ originally exerts less domestic violence than the social norm. If the social norm decreases, $H$ has the opportunity to decrease domestic violence even more because the deviation has become less painful. Thus, the effect of a change in the social norm on equilibrium violence is weakly negative.

As described above, psychologists distinguish between descriptive norms, which describe perceptions of actual outcomes, from prescriptive norms, which describe desired outcomes. Our modeling approach extends easily to these settings: if the husband incurs disutility from violating descriptive norms, his utility would decrease in deviations of his level of violence from $\phi(\bar{v})$, where $\phi(\cdot)$ maps levels of violence to perceptions, with $\phi^{\prime}>0$. Similarly, if the husband incurs disutility from violating prescriptive norms, his utility would decrease in deviations of his level of violence from an analogous function describing "acceptable" levels of violence in the village. Importantly, prescriptive norms can integrate preferences over desired levels of violence of both women and men, making it possible that changes in women's attitudes towards violence affect husband's preferred levels of violence.

We could also have used a similar approach for the wife's utility, where she incurs additional disutility $\max \{v-\bar{v}, 0\}$ or $(v-\bar{v})$. That is, $W$ incurs additional disutility if she experiences more violence than average and nothing additional otherwise, or she can even derive positive utility from experiencing less violence than average. In both types of cases, a decrease in $\bar{v}$ decreases her tolerance of violence. Again this line of reasoning extends easily to both descriptive and prescriptive norms.

\section{Intervention, experimental design, and econo- metric approach}

The intervention, experimental design, and econometric approach used in this study have previously been described by us elsewhere (Haushofer and Shapiro 2016), and are briefly summarized here. We refer the reader to the companion paper for details. 


\subsection{Intervention}

GiveDirectly, Inc. (GD; www.givedirectly.org) is an international NGO founded in 2009 whose mission is to make unconditional cash transfers to poor households in developing countries. At the time of the study, eligibility was determined by living in a house with a thatched (rather than metal) roof. Recipients were informed that they would receive a transfer of KES 25,200 (USD 404 PPP), and that this transfer was unconditional and one-time. Recipients were provided with a Safaricom SIM card and had to register it for the mobile money service M-Pesa in the name of the name of the designated transfer recipient.

\subsection{Design and timing: Main study}

An overview of the design and timeline is shown in Figure B2. Among the 120 villages with the highest proportion of thatched roofs in Rarieda district, Kenya, 60 were randomly chosen to be treatment villages. Within these villages, half of all eligible households were randomly chosen to be treatment households, while the other half were control households. A household was eligible if it had a thatched roof. This process resulted in 503 treatment households and 505 spillover households in treatment villages at baseline. Villages had an average of 100 households, of which an average of 19 percent were surveyed, and an average of 9 percent received transfers. The transfers amounted to an average of 10 percent of aggregate baseline village wealth (excluding land).

Among treatment households, we further randomized whether the transfer went to the husband or the wife (in dual-headed households). In addition, 137 households in the treatment group were randomly chosen to receive "large" transfers of KES 95,200 (USD 1,525 PPP, USD 1,000 nominal) per household, while the remaining 366 treatment households received "small" transfers of KES 25,200 (USD 404 PPP, USD 300 nominal) per household. Finally, we randomly assigned the transfer to be delivered either as a lump-sum amount or as a series of nine monthly installments. The randomization of transfer magnitude and timing is not the focus of the present paper; results have been reported elsewhere (Haushofer and Shapiro 2016). We instead focus on the randomization of recipient gender. 
We conducted a baseline survey with all treatment and spillover households before they received the first transfer, and an endline after the end of transfers. Households received the first transfer an average of 9.3 months before endline, the last transfer an average of 4.4 months before endline, and the mean transfer an average of 6.9 months before endline. ${ }^{18}$ The order in which villages were surveyed at baseline was randomized, and at endline it followed the same order. In a small number of households, the endline survey was administered before the final transfer was received. These households are nevertheless included in the analysis to be conservative (intent-to-treat).

Control villages were surveyed only at endline; in these villages, we sampled 432 "pure control" households from among eligible households. Because these pure control households were selected into the sample just before the endline, the thatched-roof criterion was applied to them about one year later than to households in treatment villages. This fact potentially introduces bias into the comparison of households in treatment and control villages; however, we showed in our previous paper (Haushofer and Shapiro 2016) that this bias was negligible, amounting to 5 households, or 1.1 percent of the sample. For this reason, and because the IPV variables, in contrast to most others studied in our previous paper, show within-village spillover effects, we use across-village treatment effect estimates for the direct treatment effect in this paper.

At endline, we observe responses to the IPV questions from women in cohabitating households in 349 treatment households, 349 spillover households, and 312 pure control households. These 1,010 households form the core analysis sample for this paper, and we restrict our analysis to this sample for all outcome variables. We observe responses from husbands in 881 (87 percent) of these households.

\subsection{Design and timing: Survey effects study}

In the main study, the treatment and spillover households were surveyed both at baseline and endline, while the pure control households were surveyed at endline only. This difference could introduce bias in the estimation of across-village

\footnotetext{
${ }^{18}$ The mean transfer date is defined as the date at which half of the total transfer amount to a given household has been sent.
} 
treatment and spillover effects if the first survey affects subsequent reports. To address this potential confound, we conducted a separate "survey effects" study in 2015, in which we directly test for the presence of such survey effects in this sample. Specifically, in 2015, we returned to administer a second endline survey to the households that originally participated in the endline survey; in addition, we used our original 2012 census of pure control villages to identify households that had been eligible to participate in the 2012 survey, but that had not previously been surveyed. There were 428 such households. We administered the same survey to this set of households in 2015 as to households involved in the original endline, with a similar temporal delay. Neither of these two groups of households received an intervention; the only difference between them is the number of surveys they completed, and comparison of the two groups therefore allows us to identify the effect on outcomes of interest of having previously been surveyed.

\subsection{Data and variables}

In each surveyed household, we collected two survey modules: a household module, which collected information about assets, consumption, income, food security, health, and education; and an individual module, which collected information about psychological wellbeing, intra-household bargaining and domestic violence, and economic preferences. The two surveys were administered on different (usually consecutive) days. The household survey was administered to any household member who could give information about the outcomes in question for the entire household; this was usually one of the primary members. The individual survey was administered to both primary members of the household, that is, husband and wife, for double-headed households; and to the single household head otherwise. During individual surveys, particular care was taken to ensure privacy; respondents were interviewed by themselves, without the interference of other household members, especially the spouse.

In this study, we focus on the female empowerment and IPV outcomes, which were collected during the individual survey. Impacts on other outcome categories have been reported in our previous paper (Haushofer and Shapiro 2016). In addition, 
the previous paper reported the reduced-form impacts on the female empowerment index described below. The IPV module was adapted from the Demographic \& Health Survey (DHS). Our outcomes of interest are reports by the woman in the household about violence perpetrated against her by the man, since most violence occurs in this direction, and reports by the woman are least likely to be subject to reporting bias. We report both individual outcome variables, as well as summary indices. These indices are created and grouped as follows:

The physical violence index is the weighted standardized average (Anderson 2008) of dummy variables indicating if in the preceding six months the woman was pushed or shaken; slapped; punched; kicked, dragged, or beaten by the husband; whether he twisted her arm or pulled her; tried to choke or burn her; or threatened to attack her. In the tables in the paper, we report the index and a subset of the constituent variables. Higher values of the index denote higher levels of physical violence.

The sexual violence index is the weighted standardized average of dummy variables indicating if in the preceding six months the husband forced the woman to have sexual intercourse or perform sexual acts. Higher values denote higher levels of sexual violence.

The female empowerment index is the weighted standardized average of a violence index and an attitude index, which in turn are constructed as follows. The violence index is a weighted standardized average of the physical and sexual violence indices described above, and an additional emotional violence index. ${ }^{19}$ The attitude index is a weighted standardized average of a male-focused attitudes index and a justifiability of violence index. ${ }^{20}$ These indices are not all presented separately

\footnotetext{
${ }^{19}$ The emotional violence index is the weighted standardized average of dummy variables indicating if in the preceding six months the man was jealous if the woman talked to other men; accused her of being unfaithful; forbade her meeting friends; limited contact with her family; didn't trust her with money; or threatened to hurt her. We do not analyze outcomes for this index separately because we trust it somewhat less than the physical and sexual violence indices, which are mostly based on tangible events such as beatings, while emotional violence may be more diffuse in nature.

${ }^{20}$ The justifiability of violence index is the weighted standardized average of dummy variables indicating if the woman or man deem it justified for the man to hit the woman if she goes out without telling him; neglects the children; argues with him; refuses to have sex with him; or burns the food. The male-focused attitudes index is the weighted standardized average of dummy variables indicating if the woman or man think that "the important decisions in the family should be made only by the men of the family"; "the wife has the right to express her opinion even when she disagrees with what her husband is saying"; "a wife should tolerate being beaten by
} 
because the focus of this paper is on physical and sexual violence. When combining these variables into the female empowerment index, we sign them such that higher values denote higher female empowerment. Note that the reduced-form impacts on the female empowerment index were reported in Haushofer and Shapiro (2016).

To measure psychological wellbeing, we use a number of standard questionnaires which are described in more detail in our original paper (Haushofer and Shapiro 2016). Higher values of the psychological well-being index denote higher psychological well-being.

To measure norms related to violence, we survey wives about whether they believe husbands have the right to beat their wives under different circumstances. The violence norms index variable is a weighted standardized average of these variables. Higher values denote stronger pro-female norms.

Finally, to measure consumption, we use total monthly household expenditure, in USD PPP. In addition, the survey module contained questions about private the consumption of both spouses. We report total private consumption for each spouse separately, which consists of the sum of variables measuring private clothing expenditure; medical expenditure; and other private expenditure.

\subsection{Integrity of experiment}

In this paper we focus on across-village comparisons between the treatment and pure control groups, and the spillover and pure control groups. Because we have no baseline data from pure control villages, we cannot run the standard baseline balance checks for these comparisons. However, the comparison of male and female recipient households is within treatment villages, and for this comparison we therefore do have baseline data. We find no significant imbalance in this comparison (Table C2). In addition, in our previous within-village analysis, we found that our study had good baseline balance on most outcomes of interest, including female empowerment (Haushofer and Shapiro 2016).

Due primarily to registration issues with $M$-Pesa, 18 treatment households had not received transfers at the time of the endline, and thus only 485 of the 503

her husband in order to keep the family together"; "a husband has the right to beat his wife"; and "it is more important to send a son to school than it is to send a daughter". 
treatment households were in fact treated. We deal with this issue by using an intent-to-treat approach.

We had low levels of attrition; overall, 940 of 1,008 baseline households (93.3 percent) were surveyed at endline. We have shown previously that our results are unlikely to be affected by this attrition (Haushofer and Shapiro 2016).

We wrote a pre-analysis plan (PAP) for this study, which is published and time-stamped at https://www.socialscienceregistry.org/trials/19. In the PAP, we specify the variables to be analyzed, the construction of indices, our approach to dealing with multiple inference, the econometric specifications to be used, and the handling of attrition. The analysis here follows this PAP, except that it focuses on one sub-group of variables for which we observed an overall treatment effect (across villages) in the main analysis reported in Haushofer and Shapiro (2016).

\subsection{Econometric approach}

\subsubsection{Direct and spillover effects of cash transfers}

Because we found a positive spillover effect on the female empowerment index in our previous paper, we here focus on across-village treatment effects. The main specification to capture the direct impact of cash transfers on recipient households, and the village-level spillover effect, is

$$
y_{v h i E}=\beta_{0}+\beta_{1} T_{v h}+\beta_{2} S_{v h}+\varepsilon_{v h i E}
$$

Here, where $y_{v h i E}$ is the outcome of interest for household $h$ in village $v$, measured at endline $(t=E)$; index $i$ is included for outcomes measured at the level of the individual respondent, and omitted for outcomes measured at the household level. $T_{v h}$ is a treatment indicator that takes value 1 for households which received a cash transfer ("treatment households") and 0 otherwise. $S_{v h}$ is a dummy variable that takes value 1 for spillover households and 0 otherwise. $\varepsilon_{v h i E}$ is the error term. The omitted category is pure control households. Thus, $\beta_{1}$ identifies the treatment effect for treated households relative to pure control households, and $\beta_{2}$ identifies within-village spillover effects by comparing spillover households to pure control households. To account for possible correlation in outcomes within villages, the 
error term is clustered at the village level. Because of the focus of this paper, the sample is restricted to co-habitating couples.

To analyze the across-village treatment effect for households in which the transfer was received by the wife vs. the husband, we estimate:

$$
y_{v h i E}=\beta_{0}+\beta_{1} T_{v h}^{\mathrm{F}}+\beta_{2} T_{v h}^{\mathrm{M}}+\beta_{3} T_{v h}^{\mathrm{W}}+\beta_{4} S_{v h}+\beta_{5} P C_{v h}^{\mathrm{SINGLE}}+\varepsilon_{v h i E}
$$

Here, $T_{v h}^{\mathrm{x}}$ indicates whether the transfer recipient is female $\left(T_{v h}^{\mathrm{F}}\right)$, male $\left(T_{v h}^{\mathrm{M}}\right)$, or that the gender of the recipient could not be randomized because the household only had one head (most commonly in the case of widows/widowers) $\left(T_{v h}^{\mathrm{W}}\right) . P C_{v h}^{\mathrm{SINGLE}}$ is an indicator for pure control households with a single head. Thus, the omitted category is cohabiting pure control households. $\beta_{1}$ identifies the treatment effect when the wife in the household receives the transfer, and $\beta_{2}$ identifies the treatment effect when the husband receives the transfer. Standard errors are again clustered at the village level. The randomizations on monthly vs. lump-sum transfers and large vs. small transfers are not the focus of this paper and are therefore not shown here.

\subsubsection{Survey effects}

Our basic specification to capture the effect of having been previously surveyed is:

$$
y_{v h i E_{2}}=\alpha_{v}+\beta_{0}+\beta_{1} D_{v h}+\varepsilon_{v h i E_{2}}
$$

Here, $y_{v h i}$ is the outcome of interest for household $h$ in village $v$, measured in the second endline $\left(t=E_{2}\right)$. The sample is restricted to households in control villages. $D_{v h}$ is a dummy variable that takes value 1 for pure control households that were surveyed in the first endline, and 0 for control village households that were not surveyed in the first endline. $\alpha_{v}$ is a village fixed effect. Thus, $\beta_{1}$ identifies the effect of having been previously surveyed. The error term is clustered at the household level when the outcomes are measured at the individual level. 


\section{Results}

\subsection{Effect of cash transfers on physical and sexual violence}

The main results are shown in Table 1. In all results tables, each row corresponds to one outcome variable, listed on the left. Column 1 shows the pure control group mean and standard deviation of that variable. The remaining columns present results from the following estimations: the main treatment effects analysis; separate regressions comparing transfers to women vs. men, and the $p$-value for the within-village difference between transfers to the female vs. the male. The final column shows the number of observations in the main sample, i.e. excluding the survey effects sample.

We find high baseline levels of domestic violence: Column 1 shows that large proportions of women in the pure control group report that their partner pushed or shook (26 percent), slapped (33 percent), punched (15 percent), or kicked, dragged, or beat (15 percent) them. Similarly, we find high baseline levels of sexual violence; 12 percent of women report having been forced to have sexual intercourse in the preceding six months, and 9 percent report having been forced to perform sexual acts.

\subsubsection{Treatment vs. pure control households}

Column 2 shows a 0.17 SD increase in female empowerment in treatment relative to pure control households. This effect is mainly driven by a reduction in physical violence by $0.21 \mathrm{SD}$; and by a reduction of $0.16 \mathrm{SD}$ in sexual violence. Among the individual variables, we find a decrease in being pushed or shaken by the husband by 7 percentage points relative to a control group mean of 27 percent (a 26 percent reduction); being slapped by the husband (11 percentage point decrease relative to 33 percent control group mean, a 33 percent reduction); being punched (6 percentage point decrease relative to 15 percent control group mean, a 39 percent reduction); and being kicked, dragged, or beaten (8 percentage point decrease relative to 15 percent control group mean, a 51 percent reduction). For sexual violence, we observe a reduction in the incidence of forced sexual intercourse by 5 percentage points relative to a control group mean of 12 percent (a 39 percent decrease), significant at the 10 percent 
level, and a 5 percentage point reduction in the incidence of being forced to perform sexual acts relative to a control group mean of 9 percent (a 52 percent reduction).

\subsubsection{Male vs. female recipient households}

Distinguishing between male and female recipient households, the treatment effect on female empowerment is driven by female recipient households, which experience a 0.29 SD increase in female empowerment relative to pure control households (column 3). The coefficient is positive ( $0.10 \mathrm{SD})$ even in male recipient households, but not significantly different from zero (column 4). We cannot reject equality of the male and female recipient coefficients (column 5). The physical violence index in female recipient households shows a significant reduction of $0.26 \mathrm{SD}$, and the sexual violence index by $0.22 \mathrm{SD}$. Male recipient households show no significant decrease in sexual violence ( $-0.10 \mathrm{SD})$, but we observe a significant $0.18 \mathrm{SD}$ reduction in physical violence in these households. The individual variables for physical violence show highly significant reductions in female recipient households. In male recipient households, the reduction in physical violence is driven by a 10 percentage point reduction in being slapped by the husband relative to a control group mean of 33 percent (a 32 percent reduction), and a 9 percentage point reduction in being kicked, dragged, or beaten relative to a control group mean of 15 percent (a 59 percent reduction). In female recipient households, rape is reduced by 7 percentage points or 56 percent, and the incidence of other sexual acts is reduced by 6 percentage points or 66 percent. Male recipient households show reductions as well, but these are not statistically significant.

Thus, we find a large and highly significant increase in female empowerment in female recipient households, and no significant decrease in male recipient households. In fact, the individual coefficients in male recipient households largely point in the direction of a decrease in IPV, and the decrease in physical violence is significant at the 5 percent level. These results are broadly consistent with the view that transfers to the woman increase the woman's bargaining power (Almås et al. 2018). 


\subsection{Effects on consumption}

Table 2 shows the impact of transfers to either spouse on overall household consumption, as well as the husband's and wife's private consumption. We find large and statistically significant increases in household consumption both for transfers to the husband (15 percent) and to the wife (15 percent), with no significant difference between the two effects. Rows 2 and 3 show that the wife's private consumption increases both after transfers to herself (91 percent) and after transfers to the husband (30 percent), although the latter effect is not statistically significant. The husband's private consumption does not show a significant treatment effect regardless of which spouse receives the transfer.

Together, the crucial insight from these results is that they are not consistent with a model in which transfers decrease the wife's consumption. This would be the prediction of a model in which within-household transfers play a role. The fact that we do not observe such evidence suggests that such transfers are not important in our setting.

\subsection{Effects on psychological wellbeing}

As an additional test of the relationships described above, we investigate whether and how changes in domestic violence are reflected in psychological wellbeing. Before doing so, two caveats are in order. First, this question cannot be answered causally here; instead, we simply ask whether treatment effects on IPV are mirrored in treatment effects on wellbeing in either partner. Second, psychological wellbeing correlates with other variables than IPV (e.g. consumption), and therefore changes in wellbeing may also reflect changes in these other variables.

With these caveats in place, we can consider treatment effects on psychological wellbeing. Tables 3 and 4 show effects of transfers on psychological well-being of the wife and the husband, respectively.

Recall that transfers to women reduce both sexual and physical violence. Are these changes reflected in the wife's psychological well-being? Indeed, for female respondents who received transfers, we find a large and significant direct treatment

effect of $0.44 \mathrm{SD}$ on the index of psychological well-being, driven by a reduction 
in stress and increases in happiness, life satisfaction, and optimism. Recall further that we observe a decrease in physical violence when husbands receive transfers. This effect, too, is mirrored in women's psychological wellbeing, with a $0.40 \mathrm{SD}$ increase in the index of psychological wellbeing among women whose husbands received transfers.

Our model suggests that husbands may derive negative utility from violence. If psychological wellbeing is closely linked to IPV, this claim makes the somewhat counterintuitive prediction that husbands should experience an increase in psychological wellbeing when transfers are made to their wife, because these transfers reduce IPV to the greatest extent. Indeed, we observe a $0.24 \mathrm{SD}$ increase in the husband's overall psychological wellbeing when his wife receives a transfer. In contrast, we observe no significant effects of transfers to the husband on his level of psychological wellbeing. One possible reason for this result is that, to the extent the husband's psychological wellbeing decreases in IPV, the effect on IPV of transfers to the husband is much smaller than that of transfers to the wife.

\subsection{Spillover and survey effects}

\subsubsection{Reduced-form effects}

Column 2 of Table 5 shows that the positive effects on female empowerment we observe after cash transfers are not restricted to treatment households: compared to pure control households, spillover households show a 0.19 SD increase in female empowerment, significant at the 5 percent level and equal in magnitude to the direct effect on treatment households ( $0.17 \mathrm{SD})$. The result is driven by a reduction in physical violence by $0.16 \mathrm{SD}$. Thus, strikingly, the receipt of cash transfers by a subset of households in the village appears to have a similarly large overall effect on neighboring households which did not receive transfers.

As described above, one potential concern about this result is that both the treatment and spillover households were surveyed twice, while the pure control households were only surveyed once (at endline). To rule out that being surveyed affects responses in a subsequent survey, we compare pure control households which were surveyed twice to pure control households which were surveyed once 
in column 3 of Table 5. We find no significant effects on any outcomes, except for an increase in reporting sexual violence as a result of being surveyed twice in the pure control group. Note, however, that this effect is only significant at the 10 percent level, and goes in the conservative direction, i.e. it shows a decrease in female empowerment as a result of more than one survey round. In addition, the overall female empowerment index is not significant. We thus conclude that survey effects are unlikely to have affected the findings on female empowerment reported above, and that they can therefore be attributed to the cash transfers.

\subsubsection{Mechanisms for spillover effects: Norm change?}

A prominent possibility to explain the large spillover effect on IPV is that the transfers changed social norms. Our survey measured norms by asking both husbands and wives whether husbands have the right to beat their wives in general, and in response to particular events, such as neglecting the children. Results on these variables are reported in Table 6. We find no significant direct or spillover effects on the index variable. Some individual coefficients point in the direction of a change towards less permissive norms around violence, and women in spillover households are 7 percentage points less likely to think that men have the right to beat them for going out without telling them, a 22 percent reduction relative to a control group mean of 32 percent; and are 6 percentage points less likely to think men have the right to beat them for refusing sex, a 22 percent reduction relative to a 28 percent control group mean. Thus, we observe some evidence that prescriptive norms among women around the husband's right to violence change in favor of the woman, but we emphasize that these results only occur for a small subset of outcome variables and not for the main index variable and should therefore be interpreted with great caution. Appendix Table C3 shows that husbands do not show a change in prescriptive norms, suggesting that if norms partly drive our empirical effects, they are more likely to do so by entering the wife's participation constraint. 


\section{Conclusion}

Intimate partner violence is a widespread phenomenon with significant welfare costs. It has previously been shown that cash transfers can be effective in reducing domestic violence, suggesting that IPV responds to income changes (Rivera-Rivera et al. 2004; Angelucci 2008; Bobonis, Gonzalez-Brenes, and Castro 2013; Hidrobo and Fernald 2013; Hidrobo, Peterman, and Heise 2016). We study the effects of an unconditional cash transfer program in Kenya in which transfers are made to either the husband or the wife on IPV. We present a theory which nests several possible determinants of violence, including resource extraction, a distaste or liking for violence, and the wife's resources and empowerment. We show that when transfers are made only to the wife, this is not sufficient for determining the underlying motives for violence based on the effects of income changes on violence. In contrast, when transfers are randomly allocated to either the husband or the wife, the resulting changes in IPV can be used to determine which motives determine equilibrium violence. We find empirically that transfers to women and men both reduce the incidence of physical IPV. Our theory shows that this result implies that violence is extractive, but also distasteful. In contrast, sexual violence is only reduced after transfers to the wife, suggesting that it may be pleasurable for the husband.

In addition, while previous studies have focused on the direct impact of transfers on recipient households, we also study non-recipients to quantify spillover effects. We find large and significant spillover effects of cash transfers on IPV, strengthening the evidence that transfers are a promising intervention to reduce IPV. Because we observe few economic spillovers (Haushofer and Shapiro 2016), this finding suggests that cash transfers may have affected social norms around IPV. In line with this view, we find suggestive evidence of changes in social norms regarding the justifiability of violence. These effects are weak, however, and require replication.

From a policy perspective, these findings have implications for the targeting of cash transfers and the development of IPV reduction programs. First, in terms

of targeting, they suggest that although cash transfers can reduce IPV regardless of who receives the transfer, transfers to female recipients are likely to be more effective, at least from the point of view of reducing IPV. In our previous work, we 
found few differences between male and female recipient households on other outcome dimensions; it is thus possible that transfers to the woman weakly dominate transfers to the man from the social planner's perspective. The spillover effects also have implications for targeting: they suggest that to maximize impacts on IPV per dollar spent, it may be optimal to not treat all households in a given location with cash transfers. Of course due to the large positive direct impacts and lack of spillovers of cash transfers on other dimensions, such selectivity also has a welfare cost; future studies might vary the proportion of households treated in a particular location to find the optimal targeting density for a given set of policy preferences.

\section{References}

Aizer, Anna. 2010. "The gender wage gap and domestic violence." American Economic Review 100 (4): 1847-1859.

Almås, Ingvild, Alex Armand, Orazio Attanasio, and Pedro Carneiro. 2018. "Measuring and Changing Control: Women's Empowerment and Targeted Transfers." The Economic Journal 128 (612): F609-F639.

Anderson, Michael. 2008. "Multiple inference and gender differences in the effects of early intervention: A reevaluation of the Abecedarian, Perry Preschool, and Early Training Projects." Journal of the American Statistical Association 103 (484): 1481-1495.

Angelucci, Manuela. 2008. "Love on the rocks: domestic violence and alcohol abuse in rural Mexico." The B.E. Journal of Economic Analysis 83 Policy 8, no. 1.

Bloch, Francis, and Vijayendra Rao. 2002. "Terror as a Bargaining Instrument: A Case Study of Dowry Violence in Rural India." American Economic Review 92 (4): 1029-1043 (September).

Bobonis, Gustavo J. 2009. "Is the allocation of resources within the household efficient? New evidence from a randomized experiment." Journal of Political Economy 117 (3): 453-503.

Bobonis, Gustavo J., Melissa Gonzalez-Brenes, and Roberto Castro. 2013. "Public transfers and domestic violence: The roles of private information and spousal control." American Economic Journal: Economic Policy 5 (1): 179-205.

Buller, Ana Maria, Amber Peterman, Meghna Ranganathan, Alexandra Bleile, Melissa Hidrobo, and Lori Heise. 2018. "A Mixed-Method Review of Cash Transfers and Intimate Partner Violence in Low- and Middle-Income Countries." The World Bank Research Observer 33 (2): 218-258 (August).

Eswaran, Mukesh, and Nisha Malhotra. 2011. "Domestic violence and women's autonomy in developing countries: theory and evidence." Canadian Journal of Economics/Revue canadienne d'économique 44 (4): 1222-1263 (November).

Farmer, Amy, and Jill Tiefenthaler. 1997. "An economic analysis of domestic violence." Review of Social Economy 55 (3): 337-358. 
Haushofer, Johannes, and Jeremy Shapiro. 2016. "The Short-Term Impact of Unconditional Cash Transfers to the Poor: Experimental Evidence from Kenya." The Quarterly Journal of Economics, July, qjw025.

Heath, Rachel, Melissa Hidrobo, and Shalini Roy. 2018. "Cash Transfers, Polygamy, and Intimate Partner Violence: Experimental Evidence from Mali." IFPRI Working Paper.

Hidrobo, Melissa, and Lia Fernald. 2013. "Cash transfers and domestic violence." Journal of Health Economics 32 (1): 304-319 (January).

Hidrobo, Melissa, Amber Peterman, and Lori Heise. 2016. "The Effect of Cash, Vouchers, and Food Transfers on Intimate Partner Violence: Evidence from a Randomized Experiment in Northern Ecuador." American Economic Journal: Applied Economics (forthcoming).

Hindin, Michelle J., Sunita Kishor, and Donna L. Ansara. 2008. "Intimate partner violence among couples in 10 DHS countries: Predictors and health outcomes."

Pollak, Robert A. 2004. "An Intergenerational Model of Domestic Violence." Journal of Population Economics 17 (2): 311-329.

Rivera-Rivera, Leonor, Eduardo Lazcano-Ponce, Jorge Salmerón-Castro, Eduardo SalazarMartínez, Roberto Castro, and Mauricio Hernández-Avila. 2004. "Prevalence and determinants of male partner violence against Mexican women: a population-based study." Salud Pública de México 46 (2): 113-122.

Roy, Shalini, Melissa Hidrobo, John Hoddinott, and Akhter Ahmed. 2018. "Transfers, Behavior Change Communication, and Intimate Partner Violence: Post-Program Evidence from Rural Bangladesh." The Review of Economics and Statistics, November, 1-45.

Stevenson, Betsey, and Justin Wolfers. 2006. "Bargaining in the shadow of the law: Divorce laws and family distress." The Quarterly Journal of Economics 121 (1): 267-288.

Tankard, Margaret. 2016. "Saving Money on Your Own or in Solidarity: An Experiment on Women's Empowerment and Intimate Partner Violence." PhD Dissertation, Princeton University.

Tankard, Margaret E., and Elizabeth Levy Paluck. 2016. "Norm Perception as a Vehicle for Social Change." Social Issues and Policy Review 10 (1): 181-211 (January).

Tauchen, Helen V., Ann Dryden Witte, and Sharon K. Long. 1991. "Domestic violence: A non-random affair." Working Paper 1665, National Bureau of Economic Research.

Zwane, A., J. Zinman, E. VanDusen, W. Pariente, C. Null, E. Miguel, M. Kremer, D. Karlan, R. Hornbeck, X. Gine, E. Duflo, F. DeVoto, B. Crepon, and A. Banerjee. 2011. "Being Surveyed Can Change Later Behavior and Related Parameter Estimates." Proceedings of the National Academy of Sciences 108 (5): 1821-1826. 
Table 1: Effects of cash transfers on violence

\begin{tabular}{|c|c|c|c|c|c|c|}
\hline & $\begin{array}{c}(1) \\
\text { Control } \\
\text { mean }(\mathrm{SD})\end{array}$ & $\begin{array}{c}(2) \\
\text { Treatment } \\
\text { (across village) }\end{array}$ & $\begin{array}{c}(3) \\
\text { Female } \\
\text { recipient }\end{array}$ & $\begin{array}{c}(4) \\
\text { Male } \\
\text { recipient }\end{array}$ & $\begin{array}{c}(5) \\
\text { Female vs. } \\
\text { male p-value }\end{array}$ & $\begin{array}{l}\text { (6) } \\
\mathrm{N}\end{array}$ \\
\hline Female empowerment index & $\begin{array}{c}0.00 \\
(1.00)\end{array}$ & $\begin{array}{c}0.17^{* *} \\
(0.07)\end{array}$ & $\begin{array}{l}0.25^{* * *} \\
(0.08)\end{array}$ & $\begin{array}{c}0.09 \\
(0.10)\end{array}$ & 0.10 & 1010 \\
\hline Physical violence index & $\begin{array}{r}-0.00 \\
(1.00)\end{array}$ & $\begin{array}{c}-0.21^{* * *} \\
(0.07)\end{array}$ & $\begin{array}{c}-0.26^{* * *} \\
(0.08)\end{array}$ & $\begin{array}{c}-0.18^{* *} \\
(0.09)\end{array}$ & 0.39 & 1010 \\
\hline Pushed or shook you & $\begin{array}{c}0.27 \\
(0.45)\end{array}$ & $\begin{array}{c}-0.07^{* *} \\
(0.03)\end{array}$ & $\begin{array}{c}-0.09^{* *} \\
(0.04)\end{array}$ & $\begin{array}{c}-0.05 \\
(0.04)\end{array}$ & 0.29 & 1010 \\
\hline Slapped you & $\begin{array}{c}0.33 \\
(0.47)\end{array}$ & $\begin{array}{c}-0.11^{* * *} \\
(0.04)\end{array}$ & $\begin{array}{c}-0.13^{* * *} \\
(0.04)\end{array}$ & $\begin{array}{c}-0.10^{* *} \\
(0.04)\end{array}$ & 0.48 & 1010 \\
\hline Punched you & $\begin{array}{c}0.15 \\
(0.36)\end{array}$ & $\begin{array}{c}-0.06^{* *} \\
(0.03)\end{array}$ & $\begin{array}{c}-0.08^{* * *} \\
(0.03)\end{array}$ & $\begin{array}{r}-0.05 \\
(0.03)\end{array}$ & 0.51 & 1010 \\
\hline Kicked, dragged, or beat you & $\begin{array}{c}0.15 \\
(0.36)\end{array}$ & $\begin{array}{c}-0.08^{* * *} \\
(0.03)\end{array}$ & $\begin{array}{c}-0.08^{* * *} \\
(0.03)\end{array}$ & $\begin{array}{c}-0.09^{* * *} \\
(0.03)\end{array}$ & 0.67 & 1010 \\
\hline Sexual violence index & $\begin{array}{r}-0.00 \\
(1.00)\end{array}$ & $\begin{array}{c}-0.16^{* *} \\
(0.08)\end{array}$ & $\begin{array}{c}-0.22^{* * *} \\
(0.08)\end{array}$ & $\begin{array}{c}-0.10 \\
(0.10)\end{array}$ & 0.23 & 1010 \\
\hline Forced sexual intercourse & $\begin{array}{c}0.12 \\
(0.33)\end{array}$ & $\begin{array}{r}-0.05^{*} \\
(0.03)\end{array}$ & $\begin{array}{c}-0.07^{* *} \\
(0.03)\end{array}$ & $\begin{array}{r}-0.03 \\
(0.03)\end{array}$ & 0.29 & 1010 \\
\hline Forced sexual acts & $\begin{array}{c}0.09 \\
(0.29)\end{array}$ & $\begin{array}{c}-0.05^{* *} \\
(0.02)\end{array}$ & $\begin{array}{c}-0.06^{* * *} \\
(0.02)\end{array}$ & $\begin{array}{r}-0.03 \\
(0.03)\end{array}$ & 0.21 & 1010 \\
\hline
\end{tabular}

Notes: OLS estimates of treatment effects. Outcome variables are listed on the left. For each outcome variable, we report the coefficients of interest and their standard errors in parentheses. Column (1) reports the mean and standard deviation of the control group for a given outcome variable. Column (2) reports the basic treatment effect calculated across villages, i.e. comparing treatment households to pure control households. Columns (3) and (4) report the effect of transfers to the husband and wife in the household, respectively, compared to pure control. Column (5) reports $p$-values for the difference between transfers to the husband and wife, using village-level fixed effects. Column (6) reports the sample size. The unit of observation is the individual; we analyze the responses of the wife. ${ }^{*}$ denotes significance at 10 pct., ${ }^{* *}$ at 5 pct., and ${ }^{* * *}$ at 1 pct. level. 
Table 2: Effects of cash transfers on consumption

\begin{tabular}{|c|c|c|c|c|c|c|}
\hline & $\begin{array}{c}(1) \\
\text { Control } \\
\text { mean (SD) }\end{array}$ & $\begin{array}{c}(2) \\
\text { Treatment } \\
\text { (across village) }\end{array}$ & $\begin{array}{c}(3) \\
\text { Female } \\
\text { recipient }\end{array}$ & $\begin{array}{c}(4) \\
\text { Male } \\
\text { recipient }\end{array}$ & $\begin{array}{c}(5) \\
\text { Female vs. } \\
\text { male p-value }\end{array}$ & $\begin{array}{l}(6) \\
\mathrm{N}\end{array}$ \\
\hline Total household expenditure (USD PPP, monthly) & $\begin{array}{l}176.88 \\
(89.75)\end{array}$ & $\begin{array}{c}26.28^{* * *} \\
(9.24)\end{array}$ & $\begin{array}{l}25.75^{* *} \\
(10.09)\end{array}$ & $\begin{array}{c}26.86^{* *} \\
(12.37)\end{array}$ & 0.81 & 1010 \\
\hline Wife's private expenditure (USD PPP, monthly) & $\begin{array}{c}3.76 \\
(8.58)\end{array}$ & $\begin{array}{l}2.39^{* * *} \\
(0.82)\end{array}$ & $\begin{array}{l}3.44^{* * *} \\
(1.15)\end{array}$ & $\begin{array}{c}1.12 \\
(1.01)\end{array}$ & 0.14 & 1010 \\
\hline Husband's private expenditure (USD PPP, monthly) & $\begin{array}{c}3.04 \\
(7.77)\end{array}$ & $\begin{array}{r}-0.13 \\
(0.63)\end{array}$ & $\begin{array}{r}-0.49 \\
(0.67)\end{array}$ & $\begin{array}{r}-0.09 \\
(0.74)\end{array}$ & 0.76 & 1010 \\
\hline
\end{tabular}

Notes: OLS estimates of treatment effects. Outcome variables are listed on the left. For each outcome variable, we report the coefficients of interest and their standard errors in parentheses. Column (1) reports the mean and standard deviation of the control group for a given outcome variable. Column (2) reports the basic treatment effect calculated across villages, i.e. comparing treatment households to pure control households. Columns (3) and (4) report the effect of transfers to the husband and wife in the household, respectively, compared to pure control. Column (5) reports $p$-values for the difference between transfers to the husband and wife, using village-level fixed effects. Column (6) reports the sample size. The unit of observation is the household. The sample is restricted to co-habitating couples. ${ }^{*}$ denotes significance at 10 pct., ${ }^{* *}$ at 5 pct., and ${ }^{* * *}$ at 1 pct. level. 
Table 3: Effects of cash transfers on psychological wellbeing (female reports)

\begin{tabular}{|c|c|c|c|c|c|c|c|c|}
\hline & $\begin{array}{c}(1) \\
\text { Control } \\
\text { mean (SD) }\end{array}$ & $\begin{array}{c}(2) \\
\text { Treatment } \\
\text { (across village) }\end{array}$ & $\begin{array}{c}(3) \\
\text { Spillover } \\
\text { effect }\end{array}$ & $\begin{array}{c}(4) \\
\text { Survey } \\
\text { effect }\end{array}$ & $\begin{array}{c}(5) \\
\text { Female } \\
\text { recipient }\end{array}$ & $\begin{array}{c}(6) \\
\text { Male } \\
\text { recipient }\end{array}$ & $\begin{array}{c}(7) \\
\text { Female vs. } \\
\text { male p-value }\end{array}$ & $\begin{array}{l}\text { (8) } \\
\mathrm{N}\end{array}$ \\
\hline Psychological well-being index & $\begin{array}{c}0.00 \\
(1.00)\end{array}$ & $\begin{array}{l}0.42^{* * *} \\
(0.10)\end{array}$ & $\begin{array}{c}0.15 \\
(0.09)\end{array}$ & $\begin{array}{c}-0.06 \\
(0.08)\end{array}$ & $\begin{array}{l}0.44^{* * *} \\
(0.10)\end{array}$ & $\begin{array}{l}0.40^{* * *} \\
(0.12)\end{array}$ & 0.54 & 1010 \\
\hline Depression (CESD) & $\begin{array}{l}26.54 \\
(8.87)\end{array}$ & $\begin{array}{c}-1.16 \\
(0.79)\end{array}$ & $\begin{array}{c}0.42 \\
(0.86)\end{array}$ & $\begin{array}{c}0.15 \\
(0.83)\end{array}$ & $\begin{array}{c}-1.04 \\
(0.89)\end{array}$ & $\begin{array}{c}-1.21 \\
(0.98)\end{array}$ & 0.79 & 1010 \\
\hline Stress (Cohen) & $\begin{array}{c}-0.00 \\
(1.00)\end{array}$ & $\begin{array}{c}-0.21^{* *} \\
(0.10)\end{array}$ & $\begin{array}{c}-0.01 \\
(0.09)\end{array}$ & $\begin{array}{c}0.07 \\
(0.08)\end{array}$ & $\begin{array}{r}-0.21^{*} \\
(0.11)\end{array}$ & $\begin{array}{c}-0.19 \\
(0.12)\end{array}$ & 0.74 & 1010 \\
\hline Happiness (WVS) & $\begin{array}{c}0.00 \\
(1.00)\end{array}$ & $\begin{array}{l}0.34^{* * *} \\
(0.08)\end{array}$ & $\begin{array}{c}0.12 \\
(0.08)\end{array}$ & $\begin{array}{c}-0.11 \\
(0.08)\end{array}$ & $\begin{array}{l}0.33^{* * *} \\
(0.10)\end{array}$ & $\begin{array}{l}0.30^{* * *} \\
(0.11)\end{array}$ & 0.77 & 1010 \\
\hline Life satisfaction (WVS) & $\begin{array}{c}0.00 \\
(1.00)\end{array}$ & $\begin{array}{l}0.35^{* * *} \\
(0.11)\end{array}$ & $\begin{array}{c}0.14 \\
(0.11)\end{array}$ & $\begin{array}{c}0.05 \\
(0.08)\end{array}$ & $\begin{array}{l}0.25^{* *} \\
(0.11)\end{array}$ & $\begin{array}{l}0.43^{* * *} \\
(0.14)\end{array}$ & $0.09^{*}$ & 1010 \\
\hline Trust (WVS) & $\begin{array}{c}-0.00 \\
(1.00)\end{array}$ & $\begin{array}{r}-0.15^{*} \\
(0.09)\end{array}$ & $\begin{array}{c}-0.18^{* *} \\
(0.09)\end{array}$ & $\begin{array}{c}-0.22^{* * *} \\
(0.08)\end{array}$ & $\begin{array}{c}-0.15 \\
(0.10)\end{array}$ & $\begin{array}{r}-0.17^{*} \\
(0.10)\end{array}$ & 0.92 & 1010 \\
\hline Locus of control & $\begin{array}{c}-0.00 \\
(1.00)\end{array}$ & $\begin{array}{c}-0.03 \\
(0.08)\end{array}$ & $\begin{array}{c}-0.19^{* *} \\
(0.09)\end{array}$ & $\begin{array}{c}-0.01 \\
(0.09)\end{array}$ & $\begin{array}{l}0.04 \\
(0.10)\end{array}$ & $\begin{array}{c}-0.11 \\
(0.10)\end{array}$ & 0.21 & 1010 \\
\hline Optimism (Scheier) & $\begin{array}{c}0.00 \\
(1.00)\end{array}$ & $\begin{array}{c}0.17^{*} \\
(0.09)\end{array}$ & $\begin{array}{c}0.07 \\
(0.09)\end{array}$ & $\begin{array}{c}-0.02 \\
(0.08)\end{array}$ & $\begin{array}{c}0.20^{*} \\
(0.12)\end{array}$ & $\begin{array}{c}0.15 \\
(0.10)\end{array}$ & 0.65 & 1010 \\
\hline Self-esteem (Rosenberg) & $\begin{array}{c}-0.00 \\
(1.00)\end{array}$ & $\begin{array}{c}-0.13 \\
(0.10)\end{array}$ & $\begin{array}{c}-0.08 \\
(0.09)\end{array}$ & $\begin{array}{c}0.09 \\
(0.08)\end{array}$ & $\begin{array}{c}-0.01 \\
(0.10)\end{array}$ & $\begin{array}{c}-0.23^{* *} \\
(0.11)\end{array}$ & $0.07^{*}$ & 1010 \\
\hline
\end{tabular}

Notes: OLS estimates of treatment, spillover, and survey effects. Outcome variables are listed on the left. For each outcome variable, we report the coefficients of interest and their standard errors in parentheses. Column (1) reports the mean and standard deviation of the control group for a given outcome variable. Column (2) reports the basic treatment effect calculated across villages, i.e. comparing treatment households to pure control households. Column (3) reports the spillover effect, i.e. comparing control households in treatment villages to control households in control villages. Column (4) reports survey effects comparing control households in control villages to a new sample of households in control villages who had not previously been surveyed. Note that this comparison uses results from endline 2. Columns (5) and (6) report the effect of transfers to the wife and husband in the household, respectively, compared to pure control. Column (7) reports $p$-values for the difference between transfers to the husband and wife, using village-level fixed effects. Column (8) reports the sample size. The unit of observation is the individual; we analyze the responses of the wife. The sample is restricted to co-habitating couples. ${ }^{*}$ denotes significance at 10 pct., ${ }^{* *}$ at 5 pct., and ${ }^{* * *}$ at 1 pct. level. 
Table 4: Effects of cash transfers on psychological wellbeing (male reports)

\begin{tabular}{|c|c|c|c|c|c|c|c|c|}
\hline & $\begin{array}{c}(1) \\
\text { Control } \\
\text { mean (SD) }\end{array}$ & $\begin{array}{c}(2) \\
\text { Treatment } \\
\text { (across village) }\end{array}$ & $\begin{array}{c}\text { (3) } \\
\text { Spillover } \\
\text { effect }\end{array}$ & $\begin{array}{c}(4) \\
\text { Survey } \\
\text { effect }\end{array}$ & $\begin{array}{c}(5) \\
\text { Female } \\
\text { recipient }\end{array}$ & $\begin{array}{c}(6) \\
\text { Male } \\
\text { recipient }\end{array}$ & $\begin{array}{c}(7) \\
\text { Female vs. } \\
\text { male p-value }\end{array}$ & $\begin{array}{l}(8) \\
\mathrm{N}\end{array}$ \\
\hline Psychological well-being index & $\begin{array}{c}0.00 \\
(1.00)\end{array}$ & $\begin{array}{c}0.12 \\
(0.11)\end{array}$ & $\begin{array}{c}-0.17 \\
(0.11)\end{array}$ & $\begin{array}{c}-0.02 \\
(0.09)\end{array}$ & $\begin{array}{c}0.24^{*} \\
(0.12)\end{array}$ & $\begin{array}{c}-0.01 \\
(0.12)\end{array}$ & 0.13 & 881 \\
\hline Depression (CESD) & $\begin{array}{l}25.79 \\
(9.63)\end{array}$ & $\begin{array}{c}-1.22 \\
(1.15)\end{array}$ & $\begin{array}{c}-0.14 \\
(1.18)\end{array}$ & $\begin{array}{c}-0.14 \\
(0.86)\end{array}$ & $\begin{array}{c}-2.05 \\
(1.26)\end{array}$ & $\begin{array}{c}-0.28 \\
(1.26)\end{array}$ & 0.11 & 881 \\
\hline Stress (Cohen) & $\begin{array}{c}0.00 \\
(1.00)\end{array}$ & $\begin{array}{c}-0.15 \\
(0.11)\end{array}$ & $\begin{array}{c}0.26^{*} \\
(0.13)\end{array}$ & $\begin{array}{r}-0.10 \\
(0.09)\end{array}$ & $\begin{array}{c}-0.17 \\
(0.13)\end{array}$ & $\begin{array}{c}-0.16 \\
(0.12)\end{array}$ & 0.92 & 881 \\
\hline Happiness (WVS) & $\begin{array}{c}0.00 \\
(1.00)\end{array}$ & $\begin{array}{c}0.14^{*} \\
(0.08)\end{array}$ & $\begin{array}{c}0.10 \\
(0.09)\end{array}$ & $\begin{array}{r}-0.08 \\
(0.09)\end{array}$ & $\begin{array}{c}0.18^{*} \\
(0.11)\end{array}$ & $\begin{array}{c}0.11 \\
(0.11)\end{array}$ & 0.48 & 881 \\
\hline Life satisfaction (WVS) & $\begin{array}{c}-0.00 \\
(1.00)\end{array}$ & $\begin{array}{c}0.08 \\
(0.12)\end{array}$ & $\begin{array}{c}-0.17 \\
(0.12)\end{array}$ & $\begin{array}{c}-0.08 \\
(0.09)\end{array}$ & $\begin{array}{c}0.11 \\
(0.12)\end{array}$ & $\begin{array}{c}0.05 \\
(0.14)\end{array}$ & 0.82 & 881 \\
\hline Trust (WVS) & $\begin{array}{c}-0.00 \\
(1.00)\end{array}$ & $\begin{array}{c}0.07 \\
(0.11)\end{array}$ & $\begin{array}{c}0.06 \\
(0.10)\end{array}$ & $\begin{array}{r}-0.00 \\
(0.09)\end{array}$ & $\begin{array}{c}0.17 \\
(0.13)\end{array}$ & $\begin{array}{c}0.00 \\
(0.13)\end{array}$ & 0.11 & 881 \\
\hline Locus of control & $\begin{array}{c}0.00 \\
(1.00)\end{array}$ & $\begin{array}{c}-0.10 \\
(0.10)\end{array}$ & $\begin{array}{c}-0.01 \\
(0.10)\end{array}$ & $\begin{array}{c}0.05 \\
(0.10)\end{array}$ & $\begin{array}{c}-0.15 \\
(0.11)\end{array}$ & $\begin{array}{c}-0.02 \\
(0.11)\end{array}$ & 0.48 & 881 \\
\hline Optimism (Scheier) & $\begin{array}{c}-0.00 \\
(1.00)\end{array}$ & $\begin{array}{c}0.17 \\
(0.11)\end{array}$ & $\begin{array}{c}0.06 \\
(0.11)\end{array}$ & $\begin{array}{c}0.03 \\
(0.10)\end{array}$ & $\begin{array}{c}0.19 \\
(0.12)\end{array}$ & $\begin{array}{c}0.07 \\
(0.13)\end{array}$ & 0.35 & 881 \\
\hline Self-esteem (Rosenberg) & $\begin{array}{c}-0.00 \\
(1.00)\end{array}$ & $\begin{array}{c}0.03 \\
(0.10)\end{array}$ & $\begin{array}{c}0.02 \\
(0.09)\end{array}$ & $\begin{array}{c}0.11 \\
(0.09)\end{array}$ & $\begin{array}{c}0.10 \\
(0.13)\end{array}$ & $\begin{array}{c}-0.04 \\
(0.12)\end{array}$ & 0.41 & 881 \\
\hline
\end{tabular}

Notes: OLS estimates of treatment, spillover, and survey effects. Outcome variables are listed on the left. For each outcome variable, we report the coefficients of interest and their standard errors in parentheses. Column (1) reports the mean and standard deviation of the control group for a given outcome variable. Column (2) reports the basic treatment effect calculated across villages, i.e. comparing treatment households to pure control households. Column (3) reports the spillover effect, i.e. comparing control households in treatment villages to control households in control villages. Column (4) reports survey effects comparing control households in control villages to a new sample of households in control villages who had not previously been surveyed. Note that this comparison uses results from endline 2. Columns (5) and (6) report the effect of transfers to the wife and husband in the household, respectively, compared to pure control. Column (7) reports $p$-values for the difference between transfers to the husband and wife, using village-level fixed effects. Column (8) reports the sample size. The unit of observation is the individual; we analyze the responses of the husband. The sample is restricted to co-habitating couples. ${ }^{*}$ denotes significance at 10 pct., ${ }^{* *}$ at 5 pct., and ${ }^{* * *}$ at 1 pct. level. 
Table 5: Effects of cash transfers on violence: spillover and survey effects

\begin{tabular}{ccccc}
\hline & $\begin{array}{c}(1) \\
\text { Control } \\
\text { mean (SD) }\end{array}$ & $\begin{array}{c}(2) \\
\text { Spillover } \\
\text { effect }\end{array}$ & $\begin{array}{c}(3) \\
\text { Survey } \\
\text { effect }\end{array}$ & $\begin{array}{c}(4) \\
\mathrm{N}\end{array}$ \\
\hline Female empowerment index & 0.00 & $0.19^{* *}$ & -0.04 & 1010 \\
& $(1.00)$ & $(0.08)$ & $(0.09)$ & \\
Physical violence index & -0.00 & $-0.16^{* *}$ & 0.00 & 1010 \\
& $(1.00)$ & $(0.07)$ & $(0.09)$ & \\
Pushed or shook you & 0.27 & $-0.06^{*}$ & -0.22 & 1010 \\
& $(0.45)$ & $(0.03)$ & $(0.24)$ & \\
Slapped you & 0.33 & $-0.09^{* *}$ & 0.12 & 1010 \\
& $(0.47)$ & $(0.03)$ & $(0.16)$ & \\
Punched you & 0.15 & -0.04 & -0.28 & 1010 \\
& $(0.36)$ & $(0.03)$ & $(0.28)$ & \\
Kicked, dragged, or beat you & 0.15 & -0.04 & -0.14 & 1010 \\
& $(0.36)$ & $(0.03)$ & $(0.17)$ & \\
Sexual violence index & -0.00 & -0.11 & $0.20^{*}$ & 1010 \\
Forced sexual intercourse & $(1.00)$ & $(0.08)$ & $(0.10)$ & \\
& 0.12 & -0.03 & 0.26 & 1010 \\
Forced sexual acts & $(0.33)$ & $(0.03)$ & $(0.19)$ & \\
& 0.09 & -0.03 & 0.18 & 1010 \\
& $(0.29)$ & $(0.02)$ & $(0.21)$ & \\
\hline
\end{tabular}

Notes: OLS estimates of spillover and survey effects. Outcome variables are listed on the left. For each outcome variable, we report the coefficients of interest and their standard errors in parentheses. Column (1) reports the mean and standard deviation of the control group for a given outcome variable. Column (2) reports the spillover effect, i.e. comparing spillover households to pure control households. Column (3) reports survey effects comparing pure control households to a new sample of households in control villages who had not previously been surveyed. Note that this comparison uses results from endline 2. Column (4) reports the sample size. The unit of observation is the individual; we analyze the responses of the wife. ${ }^{*}$ denotes significance at 10 pct., ${ }^{* *}$ at 5 pct., and ${ }^{* * *}$ at 1 pct. level. 
Table 6: Effects of cash transfers on violence norms (female reports)

\begin{tabular}{|c|c|c|c|c|c|c|c|c|}
\hline & $\begin{array}{c}(1) \\
\text { Control } \\
\text { mean (SD) }\end{array}$ & $\begin{array}{c}(2) \\
\text { Treatment } \\
\text { (across village) }\end{array}$ & $\begin{array}{c}(3) \\
\text { Spillover } \\
\text { effect }\end{array}$ & $\begin{array}{l}(4) \\
\text { Survey } \\
\text { effect }\end{array}$ & $\begin{array}{c}(5) \\
\text { Female } \\
\text { recipient }\end{array}$ & $\begin{array}{c}(6) \\
\text { Male } \\
\text { recipient }\end{array}$ & $\begin{array}{c}(7) \\
\text { Female vs. } \\
\text { male p-value }\end{array}$ & $\begin{array}{l}(8) \\
\mathrm{N}\end{array}$ \\
\hline Violence norms index & $\begin{array}{c}-0.00 \\
(1.00)\end{array}$ & $\begin{array}{c}0.07 \\
(0.08)\end{array}$ & $\begin{array}{c}0.11 \\
(0.08)\end{array}$ & $\begin{array}{c}0.09 \\
(0.09)\end{array}$ & $\begin{array}{c}0.13 \\
(0.09)\end{array}$ & $\begin{array}{c}0.02 \\
(0.10)\end{array}$ & 0.53 & 1010 \\
\hline Wife should tolerate being beaten & $\begin{array}{c}0.27 \\
(0.44)\end{array}$ & $\begin{array}{c}-0.05 \\
(0.04)\end{array}$ & $\begin{array}{c}-0.06 \\
(0.04)\end{array}$ & $\begin{array}{c}-0.01 \\
(0.04)\end{array}$ & $\begin{array}{r}-0.07 \\
(0.05)\end{array}$ & $\begin{array}{c}-0.04 \\
(0.05)\end{array}$ & 0.50 & 1010 \\
\hline Husband has the right to beat & $\begin{array}{c}0.48 \\
(0.50)\end{array}$ & $\begin{array}{c}-0.00 \\
(0.04)\end{array}$ & $\begin{array}{c}-0.01 \\
(0.04)\end{array}$ & $\begin{array}{c}0.01 \\
(0.04)\end{array}$ & $\begin{array}{c}-0.02 \\
(0.05)\end{array}$ & $\begin{array}{c}0.03 \\
(0.06)\end{array}$ & 0.20 & 1010 \\
\hline Right to beat: Going out without telling him & $\begin{array}{c}0.32 \\
(0.47)\end{array}$ & $\begin{array}{r}-0.03 \\
(0.04)\end{array}$ & $\begin{array}{c}-0.07^{* *} \\
(0.04)\end{array}$ & $\begin{array}{c}-0.03 \\
(0.05)\end{array}$ & $\begin{array}{c}-0.06 \\
(0.04)\end{array}$ & $\begin{array}{c}-0.01 \\
(0.05)\end{array}$ & 0.47 & 1010 \\
\hline Right to beat: Neglecting the children & $\begin{array}{c}0.53 \\
(0.50)\end{array}$ & $\begin{array}{c}0.05 \\
(0.04)\end{array}$ & $\begin{array}{c}0.02 \\
(0.04)\end{array}$ & $\begin{array}{c}0.02 \\
(0.04)\end{array}$ & $\begin{array}{c}0.03 \\
(0.05)\end{array}$ & $\begin{array}{c}0.07 \\
(0.05)\end{array}$ & 0.98 & 1010 \\
\hline Right to beat: Arguing with him & $\begin{array}{c}0.54 \\
(0.50)\end{array}$ & $\begin{array}{r}-0.05 \\
(0.04)\end{array}$ & $\begin{array}{c}-0.03 \\
(0.04)\end{array}$ & $\begin{array}{c}-0.06 \\
(0.05)\end{array}$ & $\begin{array}{r}-0.08^{*} \\
(0.05)\end{array}$ & $\begin{array}{c}-0.00 \\
(0.05)\end{array}$ & 0.20 & 1010 \\
\hline Right to beat: Refusing to have sex & $\begin{array}{c}0.28 \\
(0.45)\end{array}$ & $\begin{array}{c}-0.05 \\
(0.03)\end{array}$ & $\begin{array}{r}-0.06^{*} \\
(0.03)\end{array}$ & $\begin{array}{c}-0.05 \\
(0.04)\end{array}$ & $\begin{array}{r}-0.05 \\
(0.04)\end{array}$ & $\begin{array}{c}-0.06 \\
(0.04)\end{array}$ & 0.78 & 1010 \\
\hline Right to beat: Burning the food & $\begin{array}{c}0.15 \\
(0.36)\end{array}$ & $\begin{array}{r}-0.02 \\
(0.03)\end{array}$ & $\begin{array}{c}-0.02 \\
(0.03)\end{array}$ & $\begin{array}{c}-0.03 \\
(0.04)\end{array}$ & $\begin{array}{c}-0.02 \\
(0.04)\end{array}$ & $\begin{array}{c}-0.03 \\
(0.03)\end{array}$ & 0.26 & 1010 \\
\hline
\end{tabular}

Notes: OLS estimates of treatment, spillover, and survey effects. Outcome variables are listed on the left. For each outcome variable, we report the coefficients of interest and their standard errors in parentheses. Column (1) reports the mean and standard deviation of the control group for a given outcome variable. Column (2) reports the basic treatment effect calculated across villages, i.e. comparing treatment households to pure control households. Column (3) reports the spillover effect, i.e. comparing control households in treatment villages to control households in control villages. Column (4) reports survey effects comparing control households in control villages to a new sample of households in control villages who had not previously been surveyed. Note that this comparison uses results from endline 2. Columns (5) and (6) report the effect of transfers to the wife and husband in the household, respectively, compared to pure control. Column (7) reports $p$-values for the difference between transfers to the husband and wife, using village-level fixed effects. Column (8) reports the total sample size, including all treatment, spillover and pure control households. The unit of observation is the individual; we analyze the responses of the wife. ${ }^{*}$ denotes significance at 10 pct., ${ }^{* *}$ at 5 pct., and ${ }^{* * *}$ at 1 pct. level. 


\section{Appendix}

\section{A. Theoretical Appendix}

In this appendix we go into more detail about how we can use the relative magnitudes, on top of the signs, of the impact of cash transfers to $H$ and $W$ on IPV to further dissect the underlying motives of violence. In particular, do transfers to $H$ and $W$ reduce violence because they reduce $H$ 's overall demand for it, or because they reduce $W$ 's tolerance of it?

There are two cases for the equilibrium level of violence: (i) the husband's preferred level of violence is greater than the wife's maximally tolerated violence, $v^{H}>v^{W}$; and (ii) $v^{H} \leq v^{W}$. In case (i), equilibrium violence is disciplined by $W$ 's (in)tolerance of it, so that $v^{*}=v^{W}, P_{W}$ binds, and $W$ is left with no rents, while in

case (ii), equilibrium violence is disciplined by $H$ 's distaste for it, net of extractive value, so that $v^{*}=v^{H}$ and $P_{W}$ is slack: $W$ is left with some rents because the utility gains to $H$ from extracting more of his wife's income for private consumption are outweighed by his distaste for violence. Observe that the more sharply $H$ 's distaste increases in violence $\left(g^{\prime}(v)<<0\right)$, the more $H$ is disciplined by his own distaste for violence, rather than by his wife's (in)tolerance of it, and the more likely we are to be in case (ii). Thus, to characterize how transfers to $H$ and $W$ affect violence in equilibrium, we must first characterize how they affect $H$ and $W^{\prime} s$ preferred and maximally tolerated levels of violence, $v^{H}$ and $v^{W}$.

\section{A1 Effect of transfers on husband's preferred and wife's maximally-tolerated violence}

$H$ 's unconstrained maximizer $v^{H}$ is characterized by the first-order condition for $H$ 's utility with respect to $v$ :

$$
\frac{\partial u_{H}}{\partial c}\left(y_{H}+f\left(v^{H}, y_{W}\right)\right) \frac{\partial f}{\partial v}\left(v^{H}, y_{W}\right)=-\frac{\partial g}{\partial v}\left(v^{H}\right)
$$

$W^{\prime}$ 's maximum tolerance $v^{W}$ is characterized by her binding participation constraint $P_{W}$ : 


$$
u_{W}\left(y_{W}-f\left(v^{W}, y_{W}\right)\right)-h\left(v^{W}, y_{W}\right)=\bar{u}_{W}\left(y_{W}\right)
$$

We now examine how $v^{H}$ and $v^{W}$ move with respect to $y_{H}$.

Implicitly differentiating the condition characterizing $v^{H}$, we see that:

$$
\begin{aligned}
& \frac{\partial v^{H}}{\partial y_{H}}=\frac{-\frac{\partial^{2} u_{H}}{\partial c^{2}}}{\frac{\partial^{2} u_{H}}{\partial c^{2}}\left(\frac{\partial f}{\partial v}\right)^{2}+\frac{\partial^{2} f}{\partial v^{2}}\left(\frac{\partial u_{H}}{\partial c}\right)+\frac{\partial^{2} g}{\partial v^{2}}} \\
& \frac{\partial v^{H}}{\partial y_{W}}=\frac{-\frac{\partial^{2} u_{H}}{\partial c^{2}} \frac{\partial f}{\partial v} \frac{\partial f}{\partial y_{W}}-\left(\frac{\partial u_{H}}{\partial c}\right) \frac{\partial f}{\partial v \partial y_{W}}}{\frac{\partial^{2} u_{H}}{\partial c^{2}}\left(\frac{\partial f}{\partial v}\right)^{2}+\frac{\partial^{2} f}{\partial v^{2}}\left(\frac{\partial u_{H}}{\partial c}\right)+\frac{\partial^{2} g}{\partial v^{2}}}
\end{aligned}
$$

Note that the denominator is the same in both expressions, and is negative due to risk aversion, weak concavity of $f\left(v, y_{W}\right)$ in $v$, and concavity of $g(v)$. Clearly, $H$ 's most preferred level of violence is always decreasing in his income $y_{H}$, while the impact of an increase in $y_{W}$ is determined by the sign of $\frac{\partial f}{\partial v \partial y_{W}}$, that is, the strength of complementarity or substitutability between the use of violence and the wife's wealth in how much income can be extracted from her.

Because $y_{H}$ does not appear in $W$ 's participation constraint, it's clear that a transfer to $y_{H}$ cannot affect the level of violence at which $P_{W}$ binds. Implicitly differentiating the condition characterizing $v^{H}$ with respect to $y_{W}$, we see that:

$$
\frac{\partial v^{W}}{\partial y_{W}}=\frac{\frac{\partial u_{W}}{\partial c}\left[1-\frac{\partial f}{\partial y_{W}}\right]-\frac{\partial h}{\partial y^{w}}-\frac{\partial \bar{u}_{W}}{\partial y^{w}}}{\frac{\partial u_{W}}{\partial c}\left(\frac{\partial f}{\partial v}\right)+\frac{\partial h}{\partial v}}
$$

This yields Appendix Results 1 and 2 .

Appendix Result 1. (i) A transfer to the husband always decreases his preferred level of violence $v^{H}$.

(ii) A transfer to the husband never affects the wife's maximally tolerated violence $v^{W}$.

The intuition behind Appendix Result 1(i) is the following. A transfer to the husband leaves the wife's income unchanged, so the profitability of violence is unchanged, and $H$ 's own income (and therefore private consumption) has increased. 
Because violence is costly (distasteful), $H$ 's ideal level of violence falls. ${ }^{21}$

Appendix Result 1(ii) is explained as follows: When $H$ 's income increases, this does not affect $W$ 's maximal tolerance, since her participation only depends on her private consumption (which is just a portion of her own income), her inherent intolerance of IPV, and her outside option, where her ability to leave the marriage is a function of her own income.

Appendix Result 2 describes how $v^{H}$ and $v^{W}$ respond to $y_{W}$.

Appendix Result 2. (i) A transfer to the wife increases the husband's preferred level of violence $v^{H}$ if violence and income are complements in the extractive technology (i.e. $\frac{\partial f}{\partial v \partial y_{W}}>0$ ): the amount of income $H$ can extract from $W$ for a given level of violence increases in her income.

(ii) A transfer to the wife decreases the wife's maximally tolerated violence $v^{W}$ if violence and income are complements in the extractive technology, $W$ 's intolerance $h\left(v, y_{W}\right)$ increases strongly in her income, and/or her outside option $\bar{u}_{W}\left(y_{W}\right)$ increases strongly in her income.

The intuition for Appendix Result 2(i) is as follows: if the extractive return to violence is much higher when the wife is wealthier, then $H$ 's utility gains from increased consumption will outweigh his distaste for violence, and $v^{H}$ increases.

Moreover, under strong complements, a given level of violence extracts much more from a wife with higher income $y_{W}$. This means that the wife's utility at the pre-income-increase level of violence is now lower, reducing her tolerance. Further, a transfer to the wife reduces her maximally-tolerated violence if the increase in income exposes her to norms that are less tolerant of IPV, or empowers her to feel less tolerant of IPV. Again, this is because she has less utility at the pre-incomeincrease level of violence. Finally, if the increase in income gives her more resources to leave a bad marriage, $W$ 's maximal tolerance $v^{W}$ will also fall.

To sum up: the husband's demand for violence always decreases in his own income, while an increase in the wife's income may increase his demand if the returns to extractive violence are much higher for wealthier wives. The wife's max-

\footnotetext{
${ }^{21} \mathrm{~A}$ concrete interpretation of this result is that an increase in $H$ 's consumption that is not obtained through violence may decrease his stress and thereby decrease his impulse to release stress through violence.
} 
imal tolerance for violence decreases in her own income if her income is sufficiently empowering, and is unaffected by a change in her partner's income. However, since equilibrium violence is the minimum of the husband's demand for violence and the wife's maximal tolerance for violence, it is not enough to understand the effect of spousal transfers on the level of $v^{H}$ and $v^{W}$. The next step is to characterize the effect of spousal transfers on the conditions under which $v^{H}$ or $v^{W}$ is the minimum, and under which equilibrium violence goes up or down following these transfers.

\section{A2 Effect of transfers on equilibrium violence}

To understand when transfers to $H$ and $W$ decrease or increase equilibrium violence, however, we also need to understand how increases in $y_{H}$ and $y_{W}$ affect whether $v^{H}$ is greater than $v^{W}$ (so that $v^{*}=v^{W}$ ), or whether $v^{W}$ is greater than $v^{H}$ (so that $\left.v^{*}=v^{H}\right)$. In other words, equilibrium violence balances $H$ 's demand for violence with $W$ 's tolerance of it, and changes in spousal income affect violence by affecting this balance.

Table A1 presents the four theoretical possibilities for the effect of an increase in $y_{H}$ or $y_{W}$ (pre and post refer to before and after an increase in either spouse's income, respectively).

Table A1: Effect of transfers on violence in equilibrium: Possibilities

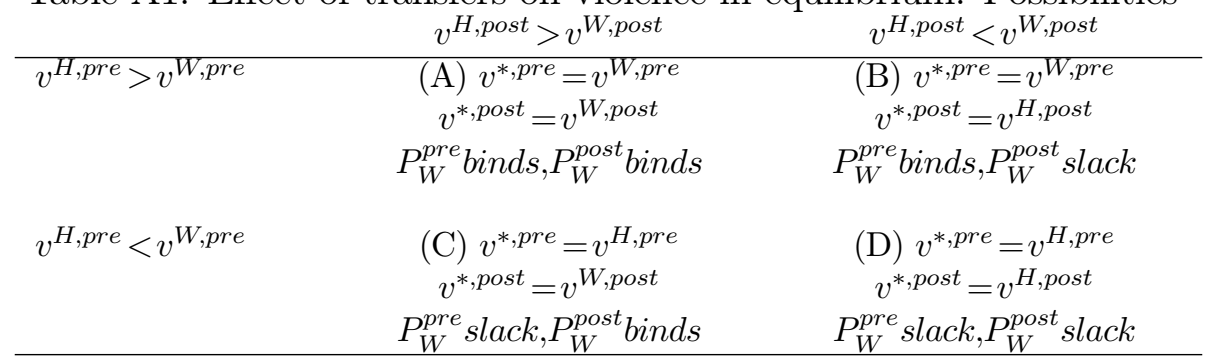

Appendix Results 3 and 4 show how we can determine which of these cases we are dealing with, and through which channel(s) the spousal transfers affect equilibrium violence. To this end, we have to examine the presence of violence in the status quo, as well as the relative magnitudes of the impact of transfers to the husband and to the wife on violence. 
Appendix Result 3. If violence is high in the status quo, and an increase in $y_{H}$ reduces violence more than an equivalent increase in $y_{W}$, then the world is in Case $B$ and transfers to the husband reduce equilibrium violence by decreasing his demand for violence.

The proof for this is as follows. Recall from Appendix Result 1 that a change in $y_{H}$ does not affect the wife's maximally tolerated level of violence, $v^{W}$. If we were in Case A, where $v^{*, p r e}=v^{W, p r e}$ and $v^{*, p o s t}=v^{W, p o s t}$, then an increase in $y_{H}$ would lead to no change in equilibrium violence: $v^{*, p r e}=v^{*, p o s t}=v^{W}$. This rules out Case A. The only way for Case $\mathrm{C}$ to arise is if the increase in $y_{H}$ caused the husband's preferred level of violence $v^{H}$ to increase (because pre-treatment, $v^{H}<v^{W}$, while post-treatment, $v^{H}>v^{W}$, where $v^{W}$ remains unchanged by Result 1). But we know from Appendix Result 1 that an increase in $y_{H}$ always decreases $v^{H}$. This rules out Case C.

Finally, Case D only arises when $H$ has a high distaste for violence: $v^{*, p r e}=v^{H, p r e}$ means that $H$ is demanding strictly less violence than $W$ tolerates in the status quo. Thus, baseline levels of violence would be low, and there wouldn't be much room for violence to be reduced. This contradicts high incidence of violence in the status quo. This leaves Case B, where the wife's participation constraint binds in the status quo and her intolerance of violence determines the equilibrium level. A transfer to the husband reduces the husband's demand for violence so that his demand now determines the equilibrium level, and the wife's participation constraint slackens and she is left with some rents.

Appendix Result 4. If violence is high in the status quo, an increase in $y_{W}$ reduces violence more than an equivalent increase in $y_{H}$, and violence and income are complements in the extractive technology, then the world is in Case A and transfers to the wife reduce equilibrium violence by decreasing her tolerance of it, through empowerment and/or resources.

Cases $\mathrm{C}$ and D contradict a high baseline level of violence (since pre-treatment, $H$ 's preferred level of violence leaves $W$ with rents). In Case $\mathrm{B}, v^{*, p r e}=v^{W, p r e}$ but $v^{*, p o s t}=v^{H, p o s t}$. Thus, for an increase in $y_{W}$ to lead to a decrease in violence in Case $\mathrm{B}$, it must be that $v^{W, p r e}>v^{H, p o s t}$, and $v^{W, p r e}<v^{H, p r e}$. However, Appendix Result 2(i) tells us that if violence and income are complements in the extractive technology, 
then an increase in $y_{W}$ causes $H$ 's preferred level of violence to increase, so that

$v^{H, p o s t}>v^{H, p r e}>v^{W, p r e}$. This rules out Case B and leaves Case A: an increase in $y_{W}$ reduces violence because the wife's intolerance of it determines the equilibrium level, and an increase in her wealth decreases her tolerance, through empowerment and/or through an increase in resources which enable her to leave an abusive marriage.

Thus, if we found that a cash transfer to $W$ reduces IPV by more than a cash transfer to $H$, we might infer that the policy-relevant determinant of violence in the setting is the wife's tolerance for it, rather than the husband's demand. This would imply that policy should focus on increasing women's empowerment and perception of violence as "normal", as well as on strengthening women's ability to leave violent marriages.

\section{A3 An Example}

We offer a numerical example to illustrate how equilibrium violence is an outcome of an interaction between instrumentality, distaste, and the participation constraint of the wife, with empowerment (norms) and her outside option as key elements of this constraint.

1. Utility: $u_{H}(c)=u_{W}(c)=\log (c), y_{H}, y_{W}>>1$

2. Extraction (instrumental violence), parametrized by $\varepsilon: f\left(v, y_{W}\right)=\varepsilon v y_{W}$, $\varepsilon \in[0,1], v \in[0,1]$

3. Distaste (expressive violence), parametrized by $\delta: g(v)=\log (1-\delta v)], \delta \in[0,1]$

4. Empowerment, parametrized by $\pi: h\left(v, y_{W}\right)=\log \left(v+\pi v y_{W}+1\right), \pi \in[0,1]$

5. Resources/Outside Option, parametrized by $r$ : $\bar{u}_{W}\left(y_{W}\right)=u_{W}\left(r(1-\epsilon v) y_{W}\right)$, $r \in[0,1]$

Assume that the wife is poorer than the husband: $y_{W}<y_{H}$.

Then the constrained maximization problem is: 


$$
\begin{gathered}
\max _{v} \log \left(y_{H}+\varepsilon v y_{W}\right)+\log (1-\delta v) \\
\text { s.t.log}\left((1-\varepsilon v) y_{W}\right)-\log \left(v+\pi v y_{W}+1\right) \geq \log \left(r(1-\varepsilon v) y_{W}\right)
\end{gathered}
$$

The unconstrained maximizer for $H$ and the binding level of violence for $W$ are:

$$
\begin{gathered}
v^{H}=\frac{1-\delta \frac{y_{H}}{y_{W}}}{\delta(1+\varepsilon)} \\
v^{W}=\frac{1-r}{r\left(1+\pi y_{W}\right)} \in[0,1]
\end{gathered}
$$

Observe that the husband's preferred level of violence $v^{H}$ decreases in his income, $y_{H}$, increases in his wife's income, $y_{W}$, decreases in the extractive efficiency of violence, $\varepsilon$, and decreases in his distaste for violence, $\delta$. The wife's maximally-tolerated level of violence decreases in her income, $y_{W}$, in empowerment, $\pi$, and in resource strength, $r$. It is unaffected by changes in her husband's income, $y_{H}$.

The condition under which the wife's participation constraint $P_{W}$ binds and $v^{*}=v^{W}=\min \left\{v^{H}, v^{W}\right\}$ is:

$$
\left(1-\frac{\delta y_{H}}{y_{W}}\right)+\pi\left(y_{W}-\delta y_{H}\right)>\delta(1+\varepsilon) \frac{(1-r)}{r}
$$

Observe that a cash transfer to $H$ makes this inequality less likely to hold: it slackens the wife's participation constraint, which means that the husband's demand for violence is lower than the wife's maximal tolerance for it, and $v^{*}=v^{H}$. Thus, a transfer to the husband increases his consumption and thereby reduces his demand for violence, and this is what leads to a fall in equilibrium violence.

By contrast, a cash transfer to $W$ makes this inequality more likely to hold: this increases the wife's empowerment and resources, causing $P_{W}$ to bind at a lower level of violence, so that it is the wife's decreased tolerance for violence that leads to a fall in equilibrium violence.

The numerical exercise is as follows. We consider different strengths of each of the four channels: distaste $\delta$, extractiveness $\varepsilon$, empowerment $\pi$, and resource strength 
$r$, for different levels of husband and wife income (the relative income is what matters). We plot $v^{H}\left(y_{H}, y_{W}\right)$ and $v^{W}\left(y_{H}, y_{W}\right)$ given the parameter environment. The lower envelope of the husband's preferred and the wife's maximally tolerated level of violence is equilibrium violence. We seek the parameter environment that best matches our empirical patterns:

1. Empirically, an increase in $y_{H}$ reduced violence. Hence, equilibrium violence must be strictly decreasing over some range of $y_{H}$.

2. An increase in $y_{W}$ reduced violence. Hence, equilibrium violence must be strictly decreasing over some range of $y_{W}$.

3. An increase in $y_{W}$ qualitatively reduced violence by more than an equivalent increase in $y_{H}$.

Requiring the patterns from the theory to be consistent with our empirical observations yields Figure B1, a parameter environment where the husband has moderate distaste for violence $(\delta=0.2)$, violence is highly extractive $(\varepsilon=1)$, and an increase in the wife's income increases her empowerment and outside option $\left(\pi=1, r=\frac{1}{3}\right)$. The blue line is the husband's demand for violence $v^{H}\left(y_{H}, y_{W}\right)$, the red line is the wife's maximal tolerance for violence $v^{W}\left(y_{H}, y_{W}\right)$, and the black line is the lower envelope $v^{*}=\min \left\{v^{H}, v^{W}\right\} .{ }^{22}$

The top panel shows how equilibrium violence changes when $y_{W}=1$ and the husband's income $y_{H}$ ranges from less than to more than his wife's. Observe that when the husband's income is less than about 4 , he wishes to use violence to extract income from his wife, but her participation constraint binds and her tolerance determines the equilibrium level. Thus, we know from Result 1 that changes in $y_{H}$ will not affect violence in equilibrium. When the husband is wealthier $\left(y_{H} \gtrsim 5\right)$, he has "enough" private consumption, and his moderate distaste for violence outweighs the amount he could extract from his relatively poor wife. Thus, his demand determines the equilibrium level of violence, and when the husband is much wealthier, his demand is zero.

The bottom panel shows how equilibrium violence changes when $y_{H}=3$ and the wife's income $y_{W}$ ranges from less than to more than her husband's. Observe

\footnotetext{
${ }^{22}$ Note that we cap the husband's demand for violence at 1 in our figure when it exceeds the wife's tolerance, for better presentation.
} 
that as the wife becomes relatively wealthier, her husband's demand for violence increases, because the value of extracting from her increases. However, at the same time, her tolerance for violence decreases - her higher income means she is more empowered and has a higher outside option. Thus, equilibrium violence is determined by the husband's (low) demand when the wife is relatively poor, but is then determined by the wife's (decreasing) tolerance. Thus, violence in equilibrium falls as the wife's income increases beyond $y_{W} \approx 1$.

The example also illustrates that a transfer to the wife may reduce violence by more than an equivalent transfer to the husband. If $y_{H}=3$ and $y_{W}=1$, the top panel shows that a unit increase in the husband's income leads no reduction in equilibrium violence, while the bottom panel shows that a unit increase in the wife's income leads to a reduction in equilibrium violence. This is because, at these initial income levels and in this parameter environment, a transfer to the wife increases her empowerment by more than the same transfer to the husband reduces his demand.

The numerical example also illustrates a suggestive insight from our theory regarding the impact of small versus large cash transfers in settings where the husband and wife are both poor but the wife is even poorer, violence is extractive but distasteful, and an increase in the wife's income increases her empowerment. Based on our theory (see ??), we suggest that in this setting, large cash transfers may actually increase IPV, and to a greater degree when given to the husband. This is because giving a large transfer to the wife will also make her a more profitable source of extraction through violence. However, transfers to the husband always weakly reduce his demand for violence, because of his distaste for it. On the other hand, if only small transfers are feasible, they may reduce IPV to a greater degree when given to the wife. These transfers empower her and decrease her tolerance for violence, without causing the husband's demand for violence to overwhelm this empowerment by making her a target for extraction. 


\section{B. Figures}

Figure B1: Numerical example of the impact of changes in husband's or wife's income on preferred and equilibrium levels of violence
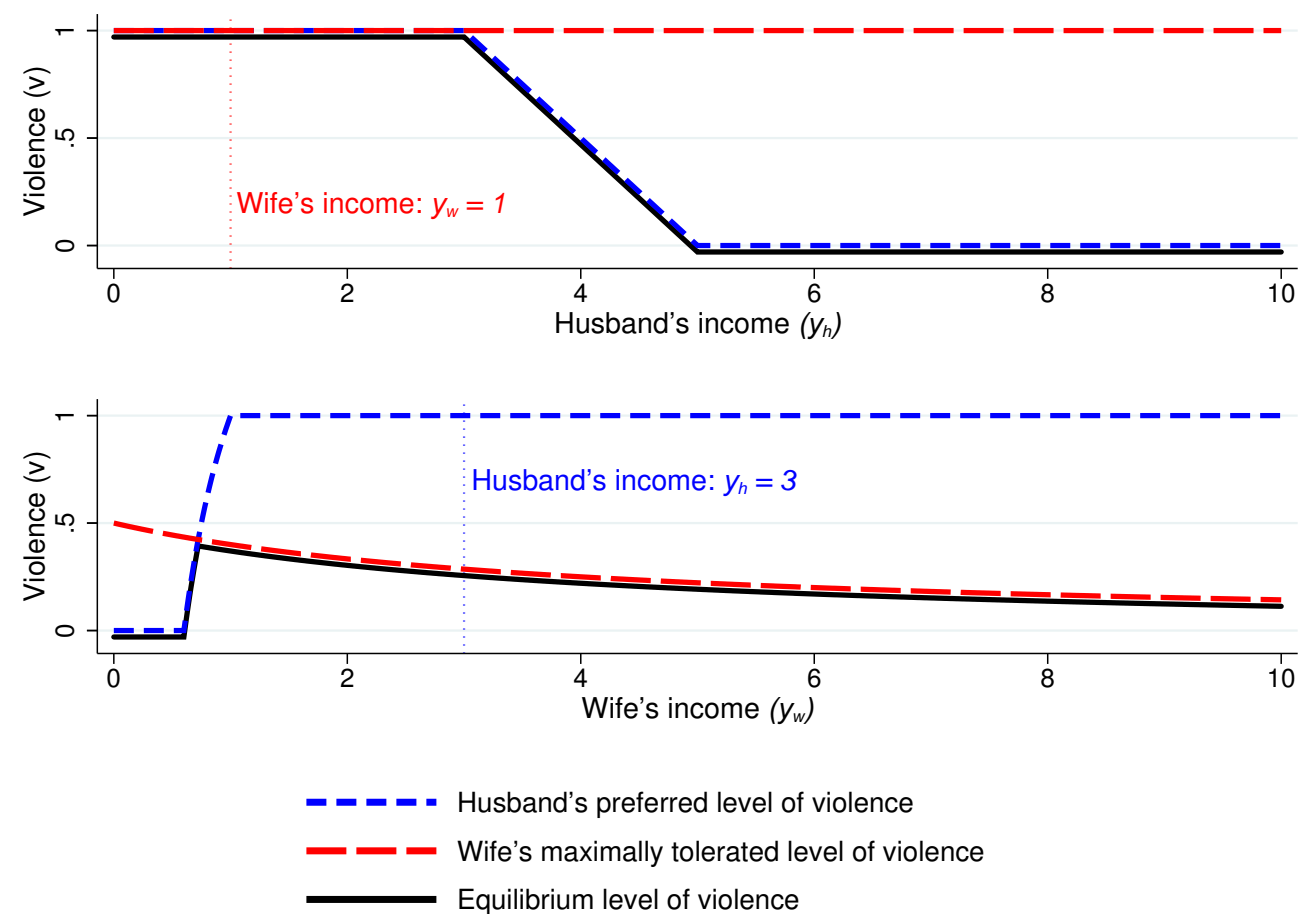
Figure B2: Timeline of study

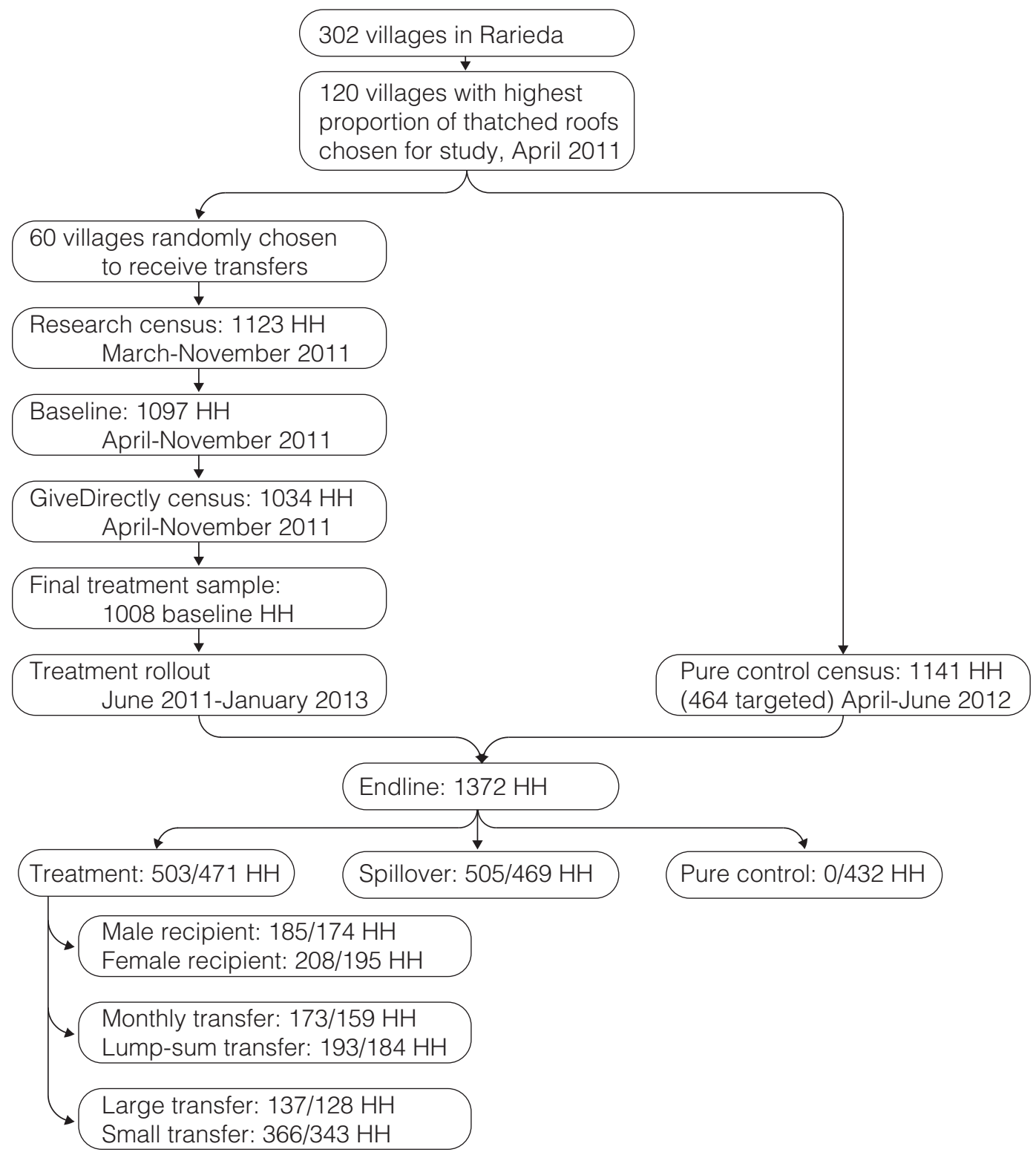




\section{Additional Tables}

Table C1: Effect of cash transfers to the husband on violence

\begin{tabular}{lccc} 
& Table C1: Effect of cash transfers to the husband on violence \\
\hline & $\begin{array}{c}\text { Expressive distaste: } \\
\text { husband dislikes violence } \\
\left(g_{v}<0\right)\end{array}$ & Not expressive & $\begin{array}{c}\text { Expressive pleasure: } \\
\text { husband likes violence } \\
\left(g_{v}>0\right)\end{array}$ \\
\hline $\begin{array}{l}\text { Not instrumental } \\
\left(f_{v}=0\right)\end{array}$ & $\begin{array}{c}\text { no effect } \\
\text { (no violence) }\end{array}$ & $\begin{array}{c}\left(g_{v}=0\right) \\
\text { no effect }\end{array}$ & no effect \\
$\begin{array}{l}\text { Instrumental } \\
\text { (violence } \\
\text { extracts) }\left(f_{v}>0\right)\end{array}$ & increase or decrease & no effect & no effect \\
\hline
\end{tabular}


Table C2: Baseline balance: Violence

\begin{tabular}{cccc}
\hline & $(1)$ & $(2)$ & $(3)$ \\
& $\begin{array}{c}\text { Control } \\
\text { mean (SD) }\end{array}$ & $\begin{array}{c}\text { Female vs. } \\
\text { male recipient }\end{array}$ & $\mathrm{N}$ \\
\hline Female empowerment index & -0.00 & 0.07 & 709 \\
& $(1.00)$ & $(0.11)$ & \\
Physical violence index & 0.96 & 0.10 & 707 \\
& $(1.72)$ & $(0.20)$ & \\
Pushed or shook you & 0.20 & 0.02 & 707 \\
& $(0.40)$ & $(0.05)$ & \\
Slapped you & 0.24 & 0.01 & 707 \\
Punched you & $(0.43)$ & $(0.05)$ & \\
& 0.14 & -0.01 & 706 \\
Kicked, dragged, or beat you & $(0.35)$ & $(0.04)$ & \\
& 0.16 & 0.03 & 706 \\
Sexual violence index & $(0.37)$ & $(0.04)$ & \\
& 0.25 & -0.08 & 705 \\
Forced sexual intercourse & $(0.63)$ & $(0.08)$ & \\
& 0.13 & -0.04 & 705 \\
Forced sexual acts & $(0.34)$ & $(0.04)$ & \\
& 0.12 & -0.03 & 705 \\
& $(0.32)$ & $(0.04)$ & \\
\hline
\end{tabular}

Notes: OLS estimates of baseline balance. Outcome variables, measured at baseline, are listed on the left. For each outcome variable, we report the coefficients of interest and their standard errors in parentheses. Column (1) reports the mean and standard deviation of the within-village control group for a given outcome variable. Column (2) reports $p$-values for the difference between transfers to the husband and wife, using village-level fixed effects. Column (3) reports the sample size. The unit of observation is the individual; we analyze the responses of the wife. ${ }^{*}$ denotes significance at 10 pct., ${ }^{* *}$ at 5 pct., and ${ }^{* * *}$ at 1 pct. level. 
Table C3: Effects of cash transfers on violence norms (male reports)

\begin{tabular}{|c|c|c|c|c|c|c|c|c|}
\hline & $\begin{array}{c}(1) \\
\text { Control } \\
\text { mean (SD) }\end{array}$ & $\begin{array}{c}(2) \\
\text { Treatment } \\
\text { (across village) }\end{array}$ & $\begin{array}{c}(3) \\
\text { Spillover } \\
\text { effect }\end{array}$ & $\begin{array}{c}(4) \\
\text { Survey } \\
\text { effect }\end{array}$ & $\begin{array}{c}(5) \\
\text { Female } \\
\text { recipient }\end{array}$ & $\begin{array}{c}(6) \\
\text { Male } \\
\text { recipient }\end{array}$ & $\begin{array}{c}(7) \\
\text { Female vs. } \\
\text { male p-value }\end{array}$ & $\begin{array}{l}(8) \\
\mathrm{N}\end{array}$ \\
\hline Violence norms index & $\begin{array}{c}0.00 \\
(1.00)\end{array}$ & $\begin{array}{r}-0.05 \\
(0.09)\end{array}$ & $\begin{array}{c}-0.10 \\
(0.09)\end{array}$ & $\begin{array}{c}-0.06 \\
(0.10)\end{array}$ & $\begin{array}{c}-0.06 \\
(0.11)\end{array}$ & $\begin{array}{c}-0.02 \\
(0.10)\end{array}$ & 0.78 & 881 \\
\hline Wife should tolerate being beaten & $\begin{array}{c}0.13 \\
(0.33)\end{array}$ & $\begin{array}{c}0.01 \\
(0.03)\end{array}$ & $\begin{array}{c}-0.01 \\
(0.03)\end{array}$ & $\begin{array}{c}0.05 \\
(0.04)\end{array}$ & $\begin{array}{c}0.01 \\
(0.04)\end{array}$ & $\begin{array}{c}0.00 \\
(0.04)\end{array}$ & 0.66 & 881 \\
\hline Husband has the right to beat & $\begin{array}{c}0.26 \\
(0.44)\end{array}$ & $\begin{array}{c}0.04 \\
(0.04)\end{array}$ & $\begin{array}{c}0.04 \\
(0.04)\end{array}$ & $\begin{array}{c}0.09^{*} \\
(0.05)\end{array}$ & $\begin{array}{c}0.03 \\
(0.05)\end{array}$ & $\begin{array}{c}0.06 \\
(0.04)\end{array}$ & 0.84 & 881 \\
\hline Right to beat: Going out without telling him & $\begin{array}{c}0.15 \\
(0.35)\end{array}$ & $\begin{array}{c}0.00 \\
(0.03)\end{array}$ & $\begin{array}{c}0.02 \\
(0.03)\end{array}$ & $\begin{array}{c}-0.04 \\
(0.05)\end{array}$ & $\begin{array}{c}-0.01 \\
(0.04)\end{array}$ & $\begin{array}{c}0.02 \\
(0.04)\end{array}$ & 0.39 & 881 \\
\hline Right to beat: Neglecting the children & $\begin{array}{c}0.32 \\
(0.47)\end{array}$ & $\begin{array}{c}0.01 \\
(0.04)\end{array}$ & $\begin{array}{c}0.06 \\
(0.04)\end{array}$ & $\begin{array}{c}-0.05 \\
(0.05)\end{array}$ & $\begin{array}{c}0.04 \\
(0.05)\end{array}$ & $\begin{array}{c}-0.04 \\
(0.05)\end{array}$ & 0.13 & 881 \\
\hline Right to beat: Arguing with him & $\begin{array}{c}0.35 \\
(0.48)\end{array}$ & $\begin{array}{c}0.00 \\
(0.04)\end{array}$ & $\begin{array}{c}0.01 \\
(0.04)\end{array}$ & $\begin{array}{c}-0.00 \\
(0.05)\end{array}$ & $\begin{array}{c}0.02 \\
(0.05)\end{array}$ & $\begin{array}{c}-0.02 \\
(0.05)\end{array}$ & 0.27 & 881 \\
\hline Right to beat: Refusing to have sex & $\begin{array}{c}0.08 \\
(0.28)\end{array}$ & $\begin{array}{c}0.02 \\
(0.02)\end{array}$ & $\begin{array}{c}0.03 \\
(0.03)\end{array}$ & $\begin{array}{c}0.04 \\
(0.04)\end{array}$ & $\begin{array}{c}0.02 \\
(0.03)\end{array}$ & $\begin{array}{c}0.02 \\
(0.03)\end{array}$ & 0.70 & 881 \\
\hline Right to beat: Burning the food & $\begin{array}{c}0.06 \\
(0.23)\end{array}$ & $\begin{array}{c}-0.00 \\
(0.02)\end{array}$ & $\begin{array}{c}0.03 \\
(0.03)\end{array}$ & $\begin{array}{c}0.01 \\
(0.03)\end{array}$ & $\begin{array}{c}-0.00 \\
(0.02)\end{array}$ & $\begin{array}{c}0.01 \\
(0.02)\end{array}$ & 0.66 & 881 \\
\hline
\end{tabular}

Notes: OLS estimates of treatment, spillover, and survey effects. Outcome variables are listed on the left. For each outcome variable, we report the coefficients of interest and their standard errors in parentheses. Column (1) reports the mean and standard deviation of the control group for a given outcome variable. Column (2) reports the basic treatment effect calculated across villages, i.e. comparing treatment households to pure control households. Column (3) reports the spillover effect, i.e. comparing control households in treatment villages to control households in control villages. Column (4) reports survey effects comparing control households in control villages to a new sample of households in control villages who had not previously been surveyed. Note that this comparison uses results from endline 2. Columns (5) and (6) report the effect of transfers to the wife and husband in the household, respectively, compared to pure control. Column (7) reports $p$-values for the difference between transfers to the husband and wife, using village-level fixed effects. Column (8) reports the sample size. The unit of observation is the individual; we analyze the responses of the husband. ${ }^{*}$ denotes significance at 10 pct., ${ }^{* *}$ at 5 pct., and ${ }^{* * *}$ at 1 pct. level. 